Supercomputing and the Finite Element Approximation of the Navier-Stokes Equations

for Incompressible Viscous Fluids

by

\title{
Roland Glowinski
}

Technical Report 88-8, June 1988 
Supercomputing and the Finite Element Approximation

of the Navier-Stokes Equations for Incompressible Viscous Fluids

\author{
Roland Glowinski \\ Rice University \\ Department of Mathematical Sciences \\ P.O. Box 1892 \\ Houston, Texas 77251 \\ and \\ University of Houston \\ Department of Mathematics \\ 4800 Calhoun \\ Houston, Texas 77004
}

\begin{abstract}
We discuss in this paper the numerical simulation of unsteady incompressible flows modeled by the Navier-Stokes equations, concentrating most particularly on flows at Reynold number of the order of $10^{3}$ to $10^{4}$. The numerical methodology described here is of modular type and well suited to super computers; it is based on time discretization by operator splitting, and space discretization by low order finite element approximations, leading to highly sparse matrices. The Stokes subproblems originating from the splitting are treated by an efficient Stokes solver, particularly efficient for flow at high Reynold numbers; the nonlinear subproblems associated with the advection are solved by a least squares/preconditioned conjugate gradient method. The methodology discussed here is then applied to the simulation of jets in a cavity, using a CRAY X-MP supercomputer. Various visualizations of the numerical results are presented, in order to show the vortex dynamics taking place in the cavity.
\end{abstract}





\section{Introduction and Synopsis}

As shown by various lectures at this meeting, finite element methods ( $h$ and $p$ versions), combined with other numerical techniques have produced efficient algorithms for the simulation of steady or unsteady flows in two and three dimensions. As well known, their main superiority on other methods lies in their ability at handling very complicated geometries; this fact was recognized a long time ago by structural engineers, and, so far, when elasticity problems are concerned, finite element techniques are definitely superior to any competitor. It is our opinion, that a similar conclusion holds for fluid flow simulation, and, for example, one of the best (if not the best) incompressible viscous flow simulators namely the ULYSSE code developed by Electricite de France (EDF) is based on finite element approximations; ULYSSE can be used for laminar and turbulent, steady and unsteady flow, and it has simulated very complicated three-dimensional flows taking place in, or around, nuclear reactors and off-shore structures.

Our goals here are more modest; concentrating on the Navier-Stokes equations for incompressibe viscous fluids, we would like to discuss some of the progress achieved during these last years concerning a particular class of finite element methods. In fact, our starting point is the lecture given in 1984 at the Israel - USA Conference on Computational Fluid dynamics and Supercomputing (see [1], [2]). Compared to [2], substantial improvements have been obtained concerning the numerical treatment of the incompressiblity condition, and also the iterative solution of the various subproblems associated with the numerical methodology. Indeed, the possibility of routinely using supercomputers has, almost paradoxically, forced us to analyze more carefully the various steps of the solution process, in order to take better advantage of the specific architecture of these new machines. This deeper understanding has implied the development of new variants of our basic algorithms, making them more efficient even on serial machines.

The content of this paper is as follows:

In section 2, we describe the Navier-Stokes equations for incompressible viscous fluids. In sections 3 and 4, we describe operator splitting methods for initial value problems, and their application to the unsteady Navier-Stokes equations. In sections 5 and 6 , we discuss the iterative solution of the basic subproblems encountered at the various steps of the solution process. In section 7 , we discuss the finite element approximation of the Navier-Stokes equations, and, finally, in section 8 , 
we discuss the results of numerical experiments showing the possibilities of the methodology which has been discussed in this paper.

2. The Navier-Stokes equations for incompressible viscous flows.

Unsteady, isothermal flows of incompressible, viscous, Newtonian fluids are modeled by the following Navier-Stokes equations

$$
\begin{aligned}
& \frac{\partial \tilde{u}}{\partial \ddot{t}}-\nu{\underset{\sim}{\nabla}}^{2} \underset{\sim}{u}+(\underset{\sim}{u} \cdot \underset{\sim}{\nabla}) \underset{\sim}{u}+\underset{\sim}{\nabla} p=\underset{\sim}{f} \text { in } \Omega \\
& \underset{\sim}{\nabla} \cdot \underset{\sim}{u}=0 \text { in } \Omega \text { (incompressibility condition). }
\end{aligned}
$$

In (2.1), (2.2), $\Omega\left(\subset \mathbb{R}^{\mathrm{N}} ; \mathrm{N}=2,3\right.$ in practice) denotes the flow region; its boundary will be denoted by $\Gamma$ and we shall denote by $x=\left\{x_{i}\right\}_{i=1}^{N}$ the generic point of $\mathbb{R}^{N}$. Also, in (2.1), (2.2)

(a) $\quad \underline{u}=\left\{u_{i}\right\}_{i=1}^{N}$ is the velocity and $\mathrm{p}$ is the pressure;

(b) $\quad \nu(>0)$ is a viscosity coefficient;

(c) $\underset{\nabla}{\nabla}=\left\{\frac{\partial}{\partial \mathrm{x}_{\mathrm{i}}}\right\}_{\mathrm{i}=1}^{\mathrm{N}}$ and $\underset{\sim}{\nabla}=\Delta=\sum_{\mathrm{i}=1}^{\mathrm{N}} \frac{\partial^{2}}{\partial \mathrm{x}_{\mathrm{i}}^{2}}$;

(d) $\quad(\underset{\sim}{\mathrm{u}} \cdot \underset{\sim}{\nabla}) \underset{\sim}{\mathrm{u}}=\left\{\sum_{\mathrm{j}=1}^{\mathrm{N}} \mathrm{u}_{\mathrm{j}} \frac{\partial \mathrm{u}_{\mathrm{i}}}{\partial \mathrm{x}_{\mathrm{j}}}\right\}_{\mathrm{i}=1}^{\mathrm{N}}$;

(e) $\quad \stackrel{f}{\mathbf{f}}=\left\{\mathbf{f}_{\mathbf{i}}\right\}_{i=1}^{\mathrm{N}}$ is a density of external forces.

Relations (2.1), (2.2) are not sufficient to define a flow; we have to consider further conditions, such as the initial condition

$$
\underline{\sim}(\mathrm{x}, 0)=\underline{\sim}_{0}(\mathrm{x})\left(\text { with } \underset{\sim}{\nabla} \cdot \underline{\sim}_{0}=0\right),
$$


and the boundary condition

$$
\underset{\sim}{\mathrm{u}}=\underset{\sim}{\mathrm{g}} \text { on } \Gamma\left(\text { with } \int_{\Gamma} \underset{\sim}{\mathrm{g}} \cdot \underset{\sim}{\mathrm{n}} \mathrm{d} \Gamma=0\right)
$$

in (2.4), $\underset{\sim}{\mathrm{n}}$ denotes the unit vector of the outward normal at $\Gamma$. More complicated boundary conditions are discussed in, e.g., [3]-[6].

The existence, and possible uniqueness of solutions for problem (2.1) - (2.4) is discussed in, e.g., [6] $[10]$.

Solving numerically $(2.1)-(2.4)$ is not at all trivial for the following reasons:

(i) Problem (2.1) - (2.4) is nonlinear;

(ii) The incompressibility condition (2.2);

(iii) It is a system of partial differential equations, coupled through the nonlinear term $(\underset{\sim}{\sim} \cdot \underset{\sim}{\nabla}) \underset{\sim}{\mathrm{u}}$ and the incompressibility condition $\underset{\sim}{\nabla} \cdot \underset{\sim}{u}=0$.

In the following section, we shall see that a time discretization by operator splitting will partly overcome the above difficulties; we shall be, in particular, able to decouple those difficulties associated to the nonlinearity with those associated to the incompressibility condition.

3. Operator splitting methods for initial value problems.

We follow here the approach in [2] and [3] (see also [12] - [15]); therefore, let's consider the following initial value problem

(3.1) $\frac{\mathrm{d} \varphi}{\mathrm{dt}}+\mathrm{A}(\varphi)=0$

$(3.2) \varphi(0)=\varphi_{0}$, 
where $\mathrm{A}$ is an operator (possibly nonlinear) from a Hilbert space $\mathrm{H}$ into itself, and where $\varphi_{0} \in \mathrm{H}$. Suppose now that operator A has the following nontrivial decomposition

(3.3) $\mathrm{A}=\mathrm{A}_{1}+\mathrm{A}_{2}$

(by nontrivial we mean that $\mathrm{A}_{1}$ and $\mathrm{A}_{2}$ are individually simpler than $\mathrm{A}$ ).

It is then quite natural to integrate the initial value problem (3.1), (3.2), by numerical methods taking advantage of the decomposition property (3.3); such a goal can be achieved by the following operator splitting schemes (where $\Delta \mathrm{t}(>0)$ is a time discretization step (supposed constant, for simplicity), and where $\varphi^{\mathrm{n}+\alpha} \sim \varphi((\mathrm{n}+\alpha) \Delta \mathrm{t})$ :

\section{A. The Peaceman-Rachford Scheme:}

$$
\varphi^{0}=\varphi_{0}
$$

then for $\mathrm{n} \geq 0$, assuming that $\varphi^{\mathrm{n}}$ is known, we compute successively $\varphi^{\mathrm{n}+1 / 2}$ and $\varphi^{\mathrm{n}+1}$ as follows:

$$
\begin{aligned}
& \frac{\varphi^{\mathrm{n}+1 / 2}-\varphi^{\mathrm{n}}}{\Delta \mathrm{t} / 2}+\mathrm{A}_{1}\left(\varphi^{\mathrm{n}+1 / 2}\right)+\mathrm{A}_{2}\left(\varphi^{\mathrm{n}}\right)=0, \\
& \frac{\varphi^{\mathrm{n}+1}-\varphi^{\mathrm{n}+1 / 2}}{\Delta \mathrm{t} / 2}+\mathrm{A}_{1}\left(\varphi^{\mathrm{n}+1 / 2}\right)+\mathrm{A}_{2}\left(\varphi^{\mathrm{n}+1}\right)=0 .
\end{aligned}
$$

Remark 3.1: The principle of scheme (3.4) - (3.6) is quite easy to understand; we integrate over [n $\Delta t$, $(\mathrm{n}+1 / 2) \Delta \mathrm{t}]($ resp. $[(\mathrm{n}+1 / 2) \Delta \mathrm{t},(\mathrm{n}+1) \Delta \mathrm{t}])$ by a scheme which is of backward (resp. forward) Euler's Type for $\mathrm{A}_{1}$, and of forward (resp. backward) Euler's Type for $\mathrm{A}_{2}$.

B. The $\theta$-scheme.

Let $\theta$ be a number in the open interval $(0,1 / 2)$; we can then integrate the initial value problem (3.1), (3.2) by the following variant of scheme (3.4) - (3.6):

$$
\varphi^{0}=\varphi_{0}
$$


then for $\mathrm{n} \geq 0$, assuming that $\varphi^{\mathrm{n}}$ is known, we compute successively $\varphi^{\mathrm{n}}+\theta, \varphi^{\mathrm{n}}+1-\theta$ and $\varphi^{n+1}$ as follows:

$$
\frac{\varphi^{\mathrm{n}+\theta}-\varphi^{\mathrm{n}}}{\theta \Delta \mathrm{t}}+\mathrm{A}_{1}\left(\varphi^{\mathrm{n}+\theta}\right)+\mathrm{A}_{2}\left(\varphi^{\mathrm{n}}\right)=0
$$

$$
\frac{\varphi^{\mathrm{n}+1-\theta}-\varphi^{\mathrm{n}+\theta}}{(1-2 \theta) \Delta \mathrm{t}}+\mathrm{A}_{1}\left(\varphi^{\mathrm{n}+\theta}\right)+\mathrm{A}_{2}\left(\varphi^{\mathrm{n}+1-\theta}\right)=0
$$

$$
\frac{\varphi^{\mathrm{n}+1}-\varphi^{\mathrm{n}+1-\theta}}{\theta \Delta \mathrm{t}}+\mathrm{A}_{1}\left(\varphi^{\mathrm{n}+1}\right)+\mathrm{A}_{2}\left(\varphi^{\mathrm{n}+1-\theta}\right)=0
$$

The stability and accuracy properties of schemes (3.4) - (3.6) and (3.7) - (3.10) are discussed in detail at least for simple model problems in [2], [12] - [14]. Operator splitting methods are also described and discussed in [16].

4. Time discretization of the Navier-Stokes equations by operator splitting methods.

There are several ways of applying the above operator splitting schemes to the time discretization of the Navier-Stokes equations (2.1) - (2.4). Concentrating on the $\theta$-scheme (3.7) - (3.10) (since it is the one providing the best numerical results) we should obtain

$$
\underline{u}^{0}=\underline{\sim}_{0}
$$

then for $\mathrm{n} \geq 0$, assuming that $\underset{\sim}{\mathrm{u}}$ is known, we compute $\left\{\underset{\sim}{\mathrm{u}+\theta}, \mathrm{p}^{\mathrm{n}+\theta}\right\}, \underset{\sim}{\mathrm{u}+1-\theta}$ and $\left\{\underset{\sim}{\mathrm{u}}{ }^{\mathrm{n}+1}, \mathrm{p}^{\mathrm{n}+1}\right\}$ as follows:

$$
\begin{aligned}
& \frac{\underbrace{\mathrm{n}+\theta}_{\mathrm{u}}-{\underset{\sim}{\mathrm{u}}}^{\mathrm{n}}}{\theta \Delta \mathrm{t}}-\alpha \nu{\underset{\sim}{\nabla}}^{2}{\underset{\sim}{\mathrm{u}}}^{\mathrm{n}+\theta}+\underset{\sim}{\nabla} \mathrm{p}^{\mathrm{n}+\theta}=\beta \nu{\underset{\sim}{\nabla}}^{2}{\underset{\sim}{\mathrm{u}}}^{\mathrm{n}}-\left(\underset{\sim}{\mathrm{u}}{ }_{\sim}^{\mathrm{n}}\right){\underset{\sim}{\mathrm{u}}}^{\mathrm{n}}+{\underset{\sim}{\mathrm{f}}}^{\mathrm{n}+\theta} \text { in } \Omega, \\
& \underset{\sim}{\mathrm{u}} \mathrm{n}+\theta=0 \text { in } \Omega, \\
& {\underset{\sim}{\mathrm{u}}}^{\mathrm{n}+\theta}={\underset{\sim}{\mathrm{g}}}^{\mathrm{n}+\theta} \text { on } \Gamma,
\end{aligned}
$$


then

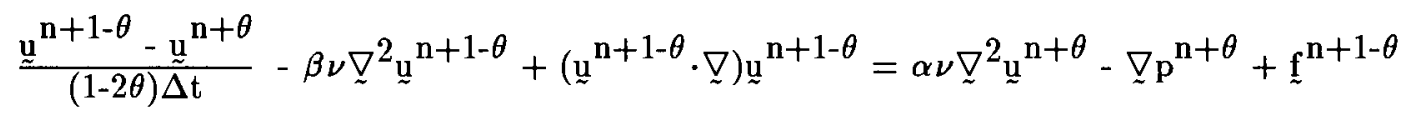
in $\Omega$,

$$
{\underset{\sim}{u}}^{\mathrm{n}+1-\theta}={\underset{\sim}{\mathrm{g}}}^{\mathrm{n}+1-\theta} \text { on } \Gamma,
$$

and finally

$$
\frac{\underline{u}^{\mathrm{u}+1}-\underline{\sim}^{\mathrm{u}+1-\theta}}{\theta \Delta \mathrm{t}}-\alpha \nu{\underset{\sim}{\nabla}}^{2}{\underset{\sim}{\mathrm{u}}}^{\mathrm{n}+1}+\nabla \mathrm{p}^{\mathrm{n}+1}=\beta \nu{\underset{\sim}{\nabla}}^{2}{\underset{\sim}{\mathrm{u}}}^{\mathrm{n}+1-\theta}-\left({\underset{\sim}{\mathrm{u}}}^{\mathrm{n}+1-\theta} \cdot \underset{\sim}{\nabla}\right){\underset{\sim}{\mathrm{u}}}^{\mathrm{n}+1-\theta}+{\underset{\sim}{\mathrm{f}}}^{\mathrm{n}+1}
$$
in $\Omega$,

$\left(^{(4.4)} \quad{\underset{\sim}{u}}^{\mathrm{n}+1}={\underset{\sim}{\mathrm{g}}}^{\mathrm{n}+1}\right.$ on $\Gamma$.

In (4.1) - (4.4), we take $\alpha, \beta \in(0,1)$ and also $\alpha+\beta=1$; actually a natural choice for $\alpha$ and $\beta$ is to take them such that $\alpha \theta=\beta(1-2 \theta)$, which then clearly implies that

$$
\alpha=(1-2 \theta) /(1-\theta), \beta=\theta /(1-\theta)
$$

with such a choice there will be a large commonality between the programs used for solving problems (4.3) and (4.2), (4.4). Concerning the choice of $\theta$ it follows from [2], [3], [13] that a "good" value is 1 $1 / \sqrt{2}$ (this choice being also supported by numerical experiments).

Iterative methods for solving subproblems (4.3) and (4.2), (4.4) will be discussed in Sections 5 and 6 , respectively. 
5. Iterative solution of the nonlinear subproblems (4.3).

Generalities and Synopsis: Problem (4.3) is clearly related to the following class of nonlinear elliptic systems

$$
\alpha \underline{\sim}-\nu{\underset{\sim}{\nabla}}^{2} \mathbf{u}+(\underline{u} \cdot \underset{\sim}{\nabla}) \underline{u}=\underset{\sim}{f} \text { in } \Omega
$$

$$
\underset{\sim}{\mathrm{u}}=\underset{\sim}{\mathrm{g}} \text { on } \Gamma \text {, }
$$

with $\alpha$ and $\nu$ two positive constants. The solution of (5.1) by Newton's method is discussed in [3]; we shall concentrate here on the solution of (5.1) by conjugate gradient algorithms, preconditioned by the elliptic operator $\alpha \mathrm{I}-\nu \nabla^{2}$; indeed, we shall not solve problem (5.1) directly, but instead a minimization problem obtained from (5.1) by a (nonlinear) least squares formulation, like those systematically discussed in [4], [17] for the solution of nonlinear boundary value problems.

Some Useful Functional Spaces and Notation: In the sequel we shall need the following Sobolev functional spaces (whose fundamental properties are discussed in, e.g., [18], [19]):

$$
\begin{aligned}
& \mathrm{H}^{1}(\Omega)=\left\{\varphi \mid \varphi \in \mathrm{L}^{2}(\Omega), \frac{\partial \varphi}{\partial \mathrm{x}_{\mathrm{i}}} \in \mathrm{L}^{2}(\Omega), \forall \mathrm{i}=1, \ldots \mathrm{N}\right\}, \\
& \mathrm{H}_{0}^{1}(\Omega)=\left\{\varphi \mid \varphi \in \mathrm{H}^{1}(\Omega), \varphi=0 \text { on } \Gamma\right\}, \\
& \mathrm{V}_{\mathrm{g}}=\left\{\underline{v} \mid \underline{\sim} \in\left(\mathrm{H}^{1}(\Omega)\right)^{\mathrm{N}}, \underline{\mathrm{v}}=\underset{\sim}{\mathrm{g}} \text { on } \Gamma\right\}, \\
& \mathrm{V}_{0}=\left(\mathrm{H}_{0}^{1}(\Omega)\right)^{\mathrm{N}} .
\end{aligned}
$$

If $g$ is sufficiently smooth, then $V_{g} \neq \emptyset$. We shall use quite frequently the following notation:

$$
\begin{aligned}
& \underset{v}{u} \cdot \underset{v}{v}=\sum_{i=1}^{N} u_{i} v_{i}, \forall \underline{u}=\left\{u_{i}\right\}_{i=1}^{N}, \forall \underline{v}=\left\{v_{i}\right\}_{i=1}^{N} \text {, } \\
& \underset{\sim}{\boldsymbol{u}} \cdot \underset{\sim}{\nabla}=\sum_{i=1}^{N} \sum_{j=1}^{N} \frac{\partial u_{i}}{\partial x_{j}} \frac{\partial v_{i}}{\partial x_{j}}, \forall \underline{u}, \underline{v}
\end{aligned}
$$




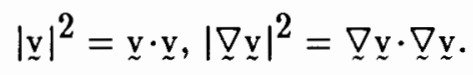

A least square formulation of the nonlinear problem (5.1):

Let's consider $\underline{\mathrm{y}} \in \mathrm{V}_{\mathrm{g}}$; from $\mathrm{y}$ we define $\underset{\sim}{\mathrm{y}}(=\underset{\sim}{\mathrm{y}}(\mathrm{v}))$, as the solution of the linear Dirichlet system

$$
\alpha \underset{\sim}{\mathrm{y}}-\nu{\underset{\sim}{\nabla}}^{2} \underset{\sim}{\mathrm{y}}=\alpha \mathbf{\sim}-\nu{\underset{\sim}{\nabla}}^{2} \mathrm{v}+(\underset{\sim}{\mathrm{v}} \cdot \underset{\sim}{\nabla}) \underset{\sim}{\mathrm{y}}-\underset{\sim}{\mathrm{f}} \text { in } \Omega
$$

$(5.6)_{2} \quad \underline{\sim}=\underset{\sim}{0}$ on $\Gamma$

if $\underset{\sim}{f}$ and $g$ are smooth enough, then problem (5.6) has a unique solution in $\mathrm{V}_{0}$.

We observe that if $\underset{\sim}{\mathrm{v}} \in \mathrm{V}_{\mathrm{g}}$ is a solution of the nonlinear problem (5.1), then the corresponding function $\underset{\sim}{\mathrm{y}}$ is equal to $\underset{\sim}{0}$; conversely if $\underset{\sim}{\mathrm{y}} \in \mathrm{V}_{\mathrm{g}}$ is such that $\underset{\sim}{\mathrm{y}}=\underset{\sim}{0}$, then $\underset{\sim}{\mathrm{y}}$ is a solution of (5.1); from these obvious observations, we associate to (5.1) the following least squares problem:

$$
\left\{\begin{array}{l}
\text { Find } u \in \mathrm{V}_{\mathrm{g}} \text { such that } \\
\mathrm{J}(\underset{\sim}{\mathrm{u}}) \leq \mathrm{J}(\underset{\sim}{\mathrm{y}}), \forall \underset{\sim}{\mathrm{v}} \in \mathrm{V}_{\mathrm{g}}
\end{array}\right.
$$

where (with $\left.\mathrm{dx}=\mathrm{dx}_{1} \ldots . . \mathrm{dx}_{\mathrm{N}}\right)$ :

$$
\mathrm{J}(\mathrm{y})=\left.\frac{\alpha}{2} \int_{\Omega} \underset{\sim}{\mid \mathrm{y}}\right|^{2} \mathrm{dx}+\frac{\nu}{2} \int_{\Omega}|\underset{\sim}{\nabla}|^{2} \mathrm{dx}
$$

$\underset{\sim}{\mathrm{y}}$ being obtained from $\mathbf{v}$, through the solution of $(5.6)$.

Conjugate Gradient Solution of the Least Squares Problem (5.7): Among the possible methods which can be used to solve the least squares problem (5.7) we shall concentrate on conjugate gradient algorithms operating in the spaces $\mathrm{V}_{\mathrm{g}}$ and $\mathrm{V}_{0}$, both equipped with the scalar product

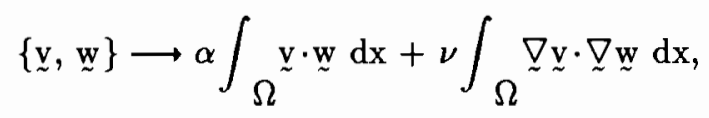


and the corresponding norm. We obtain then (cf. [3], [4], [17]):

Step 0: Initialization

$$
\underline{\sim}^{0} \in \mathrm{V}_{\mathbf{g}}, \text { given; }
$$

compute then $\mathrm{g}^{0} \in \mathrm{V}_{0}$, the solution of the linear Dirichlet system

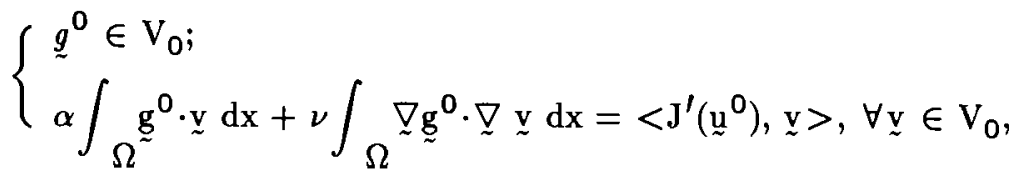

and set

$$
\underline{w}^{0}=\underline{\sim}^{0} .
$$

Then for $\mathrm{n} \geq 0$, assuming that ${\underset{\sim}{\mathrm{u}}}^{\mathrm{n}},{\underset{\sim}{\mathrm{g}}}^{\mathrm{n}},{\underset{\sim}{\mathrm{w}}}^{\mathrm{n}}$ are known, compute ${\underset{\sim}{\mathrm{u}}}^{\mathrm{n}+1},{\underset{\sim}{\mathrm{g}}}^{\mathrm{n}+1}, \underset{\sim}{\mathrm{w}}{ }^{\mathrm{n}+1}$ as follows:

Step 1: Descent

Solve

$$
\left\{\begin{array}{l}
\text { Find } \rho_{\mathrm{n}} \in \mathbb{R}, \text { such that } \\
\mathrm{J}\left({\underset{\sim}{\mathrm{\sim}}}^{\mathrm{n}}-\rho_{\mathrm{n}} \underset{\sim}{\mathrm{w}} \mathrm{n}\right) \leq \mathrm{J}\left({\underset{\sim}{\mathrm{\sim}}}^{\mathrm{n}}-\rho_{\underset{\sim}{w}}^{\mathrm{n}}\right), \forall \rho \in \mathbb{R},
\end{array}\right.
$$

and set

$$
{\underset{\sim}{u}}^{\mathrm{n}+1}={\underset{\sim}{\mathrm{u}}}^{\mathrm{n}}-\rho_{\mathrm{n}} \underline{\sim}^{\mathrm{n}} \text {. }
$$

Step 2: Constructing the New Descent Direction

$$
\text { Solve }
$$




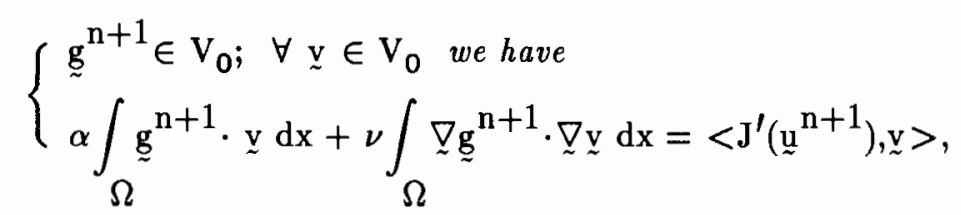

and set

$$
\gamma_{\mathrm{n}}=\frac{\alpha \int_{\Omega}\left|\mathrm{g}^{\mathrm{n}+1}\right|^{2} \mathrm{dx}+\nu \int_{\Omega}\left|\nabla \mathrm{g}^{\mathrm{n}+1}\right|^{2} \mathrm{dx}}{\alpha \int_{\Omega}\left|\mathrm{g}^{\mathrm{n}}\right|^{2} \mathrm{dx}+\nu \int_{\Omega}\left|\nabla \mathrm{g}^{\mathrm{n}}\right|^{2} \mathrm{dx}} .
$$

We update then $\underset{\sim}{\mathrm{w}}{ }^{\mathrm{n}}$ by

$$
{\underset{\sim}{w}}^{n+1}=\underline{q}^{n+1}+\gamma_{n} \stackrel{w}{n}^{n}
$$

Do $\mathrm{n}=\mathrm{n}+1$ and go to (5.12).

Algorithm (5.9) - (5.16) clearly deserves further explanation and comments; let's mention most particularly:

(i) As stopping criteria, we have been using

$$
\mathrm{J}\left(\underline{\sim}^{\mathrm{n}}\right) / \mathrm{J}\left(\underline{u}^{0}\right) \leq \epsilon
$$

with $\epsilon \sim 10^{-9}$.

(ii) In (5.10), (5.14), <•, $>$ denotes the duality paring between $\left(\mathrm{H}^{-1}(\Omega)\right)^{\mathrm{N}}$ and $\mathrm{V}_{0}\left(=\left(\mathrm{H}_{0}^{1}(\Omega)\right)^{\mathrm{N}}\right)$. We recall that $\mathrm{H}^{-1}(\Omega)$ is the dual space of $\mathrm{H}_{0}^{1}(\Omega)$ and that, $\forall \mathrm{g} \in \mathrm{H}^{-1}(\Omega)$, we have the following representation

$$
\langle\mathrm{g}, \mathrm{v}\rangle=\int_{\Omega} \mathrm{g}_{0} \mathrm{vdx}+\sum_{\mathrm{i}=1}^{\mathrm{N}} \int_{\Omega} \mathrm{g}_{\mathrm{i}} \frac{\partial \mathrm{v}}{\partial \mathrm{x}_{\mathrm{i}}} \mathrm{dx}, \forall \mathrm{v} \in \mathrm{H}_{0}^{1}(\Omega) ;
$$

in (5.18), $\mathrm{g}_{\mathbf{i}} \in \mathrm{L}^{2}(\Omega), \forall \mathrm{i}=\mathbf{0}, 1, \ldots \mathrm{N}$. 
(iii) If we denote by $\mathrm{J}^{\prime}(\underset{\sim}{\mathrm{v}})$ the differential of $\mathrm{J}_{\text {at }} \underset{\sim}{\mathrm{v}} \in \mathrm{V}_{\mathrm{g}}$ it is defined by

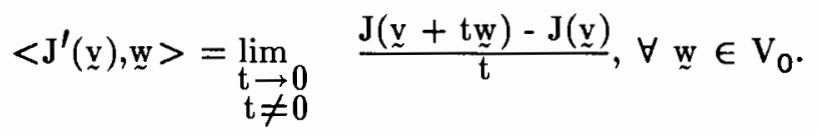

A fairly simple pertubation analysis would show that

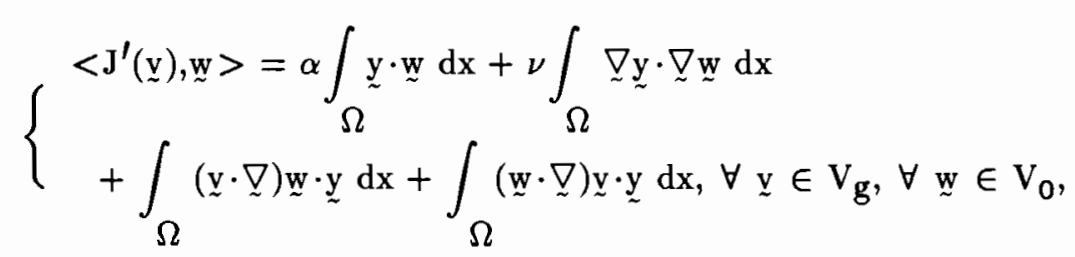

where in (5.20), $\mathrm{y}$ is the solution of (5.5) associated to $\mathrm{v}$.

(iv) A crucial step which has to be discussed with some detail is (5.12). Actually since the nonlinearity in (5.1) is quadratic it is easy to see that the function

$$
\mathrm{h}_{\mathrm{n}}: \rho \rightarrow \mathrm{J}\left({\underset{\sim}{\mathrm{u}}}^{\mathrm{n}}-\rho{\underset{\sim}{\mathrm{w}}}^{\mathrm{n}}\right)
$$

is a quartic polynomial. Therefore solving the minimization problem (5.12) can be reduced to the solution of the cubic equation $\mathrm{h}_{\mathrm{n}}^{\prime}(\rho)=0$, whose solutions are computed by the single variable Newton's method (in practice, starting from $\rho=0,2$ to 3 Newton's iterations are sufficient to accurately compute $\rho_{n}$ ). To compute the coefficients of the polynomial $h_{n}$, one has to solve two Dirichlet systems associated to the elliptic operator $\alpha \mathrm{I}-\nu \underset{\sim}{\nabla}{ }^{2}$; hence each iteration of algorithm (5.9) (5.16) requires the solution of three elliptic systems associated to $\alpha \mathrm{I}-\nu \nabla^{2}$, namely the above two, and also the elliptic system (5.14). For more details about the calculation of $\rho_{\mathrm{n}}$, see [3].

Some aspects of the finite element implementation of algorithm (5.9) - (5.16) will be discussed in Section 7.

6. Iterative solution of the linear problems (4.2) and (4.4).

6.1. Generalities.

Problems (4.2) and (4.4) are clearly particular cases of the following steady (quasi) Stokes 
problem

$$
\left\{\begin{array}{l}
\alpha \underset{\sim}{\mathrm{u}}-\nu \nabla^{2} \underline{\sim}+\underset{\sim}{\mathrm{u}}+\underset{\sim}{\mathrm{f}} \text { in } \Omega, \\
\underset{\sim}{\nabla} \cdot \underset{\sim}{\mathrm{u}}=0 \text { in } \Omega, \\
\underset{\sim}{\mathrm{u}}=\underset{\sim}{\mathrm{g}} \text { on } \Gamma\left(\text { with } \int_{\Gamma} \underset{\sim}{\mathrm{g}} \cdot \underset{\sim}{\mathrm{n}} \mathrm{d} \Gamma=0\right)
\end{array}\right.
$$

with $\alpha$ and $\nu$ two positive parameters.

It follows from [7] - [11] that problem $(6.1)$ has a unique solution in $\mathrm{V}_{\mathrm{g}} \times\left(\mathrm{L}^{2}(\Omega) / \mathbb{R}\right)$ if $\underset{\sim}{\mathrm{f}}$ and $\underset{\sim}{\mathrm{g}}$ are sufficiently smooth.

Solving problem $(6.1)$ is not trivial, mainly because the condition $\underset{\sim}{\nabla} \cdot \underset{\sim}{u}=0$. However supposing for a moment that $\mathrm{p}$ is known, then one can obtain $\underset{\sim}{\mathrm{u}}$ from the solution of a fairly simple Dirichlet problem, associated to the operator $\alpha \mathrm{I}-\nu \nabla^{2}$; this observation is, in a sense, at the foundation of the methods to be described below (see also [3]).

6.2. A functional equation satisfied by the pressure.

We suppose from now on that $\Omega$ is bounded. Let's define then $\mathrm{H}$ by

$$
H=\left\{q \mid q \in L^{2}(\Omega), \int_{\Omega} q d x=0\right\} .
$$

To $q \in H$ we associate ${\underset{\sim}{q}}_{q} \in \mathrm{V}_{0}$ by

$$
\left\{\begin{array}{l}
\alpha \underset{\sim}{\mathrm{u}} \mathrm{q}-\alpha \underset{\sim}{\nabla^{2}} \underset{\sim}{\mathrm{u}} \mathrm{q}=-\underset{\sim}{\nabla} \mathrm{q} \text { in } \Omega, \\
\underset{\sim}{\mathrm{q}}=\underset{\sim}{\mathbf{u}} \text { on } \Gamma
\end{array}\right.
$$

We define then an operator A defined over $\mathrm{H}$, by

$$
\mathrm{Aq}=\underset{\sim}{\nabla} \cdot{\underset{\sim}{\mathrm{u}}}_{\mathrm{q}} \cdot
$$

We observe that $\mathrm{Aq} \in \mathrm{L}^{2}(\Omega)$, since $\stackrel{\sim}{\mathrm{q}}_{\mathrm{q}} \in\left(\mathrm{H}_{0}^{1}(\Omega)\right)^{\mathrm{N}}$; we also have (from the divergence 
theorem, and from (6.4))

$$
\int_{\Omega} \mathrm{Aq} \mathrm{dx}=\int_{\Omega} \underset{\sim}{\nabla} \cdot{\underset{\sim}{\mathrm{u}}}_{\mathrm{q}} \mathrm{dx}=\int_{\Gamma} \underset{\sim}{\mathrm{u}} \mathrm{q} \cdot \stackrel{\sim}{\mathrm{n}} \mathrm{d} \Gamma=0,
$$

implying in turn that $A q \in H, \forall q \in H$. We have more, since $A$ is continuous from $H$ into $H$. We also have (with obvious notation)

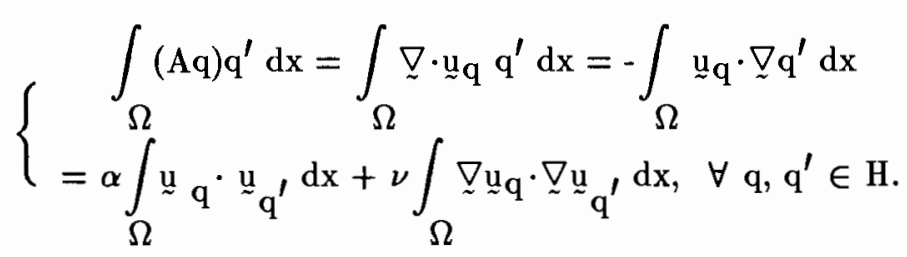

It follows from (6.5) that operator $A$ is self adjoint and strongly elliptic from $H$ onto $H$ (this last property means that there exists a constant $\gamma>0$ such that

$$
\left.\int_{\Omega}(\mathrm{Aq}) \mathrm{q} \mathrm{dx} \geq \gamma\|\mathrm{q}\|_{\mathrm{L}^{2}(\Omega)}^{2}, \forall \mathrm{q} \in \mathrm{H}\right) .
$$

Operator $\mathrm{A}$ is therefore an isomorphism from $\mathrm{H}$ onto $\mathrm{H}$.

In order to derive the equation satisfied by $p$, we introduce ${\underset{\sim}{0}}_{0} \in \mathrm{V}_{\mathrm{g}}$ satisfying

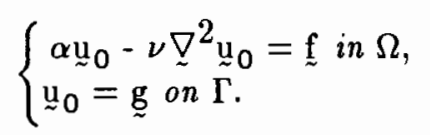

Substracting (6.6) from (6.1), we obtain

$$
\left\{\begin{array}{l}
\alpha \underset{\mathrm{u}}{\overline{\mathrm{u}}}-\nu \underset{\nabla^{2}}{\overline{\mathrm{u}}}=-\underset{\sim}{\nabla} \mathrm{p} \text { in } \Omega \\
\underset{\sim}{\mathrm{u}}=0 \text { on } \Gamma
\end{array}\right.
$$

where $\underline{\underline{u}}=\underline{u}-\underline{\sim}_{0}$.

Suppose now that we take for $p$ the unique pressure solution of $(6.1)$, satisfying $p \in H$. We have then from (6.3), (6.4) and (6.7) 


$$
\mathrm{Ap}=\underset{\sim}{\nabla} \cdot \overline{\mathrm{u}}=\underset{\sim}{\nabla}\left(\underset{\sim}{\mathbf{u}}-\underline{\sim}_{0}\right)=-\underset{\sim}{\nabla} \cdot \underline{\sim}_{0} .
$$

Since

$$
\int_{\Omega} \underset{\sim}{\nabla} \cdot{\underset{\sim}{u}}_{0} \mathrm{~d} x=\int_{\Gamma} \underset{\sim}{\mathrm{u}_{0}} \cdot \underset{\sim}{\mathrm{n}} \mathrm{d} \Gamma=\int_{\Gamma}^{\mathrm{g}} \cdot \underset{\sim}{\mathrm{n}} \mathrm{d} \Gamma=0,
$$

the right hand side of (6.8) belongs to $\mathrm{H}$ implying, since $\mathrm{A}$ is an isomorphism, that problem

$$
\operatorname{Ap}=-\underset{\sim}{\nabla} \cdot \underline{\sim}_{0}
$$

is well-posed in $\mathrm{H}$.

We observe that problem (6.9) is equivalent to the linear variational problem

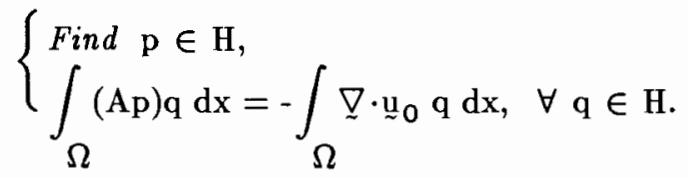

In (6.10) the bilinear form (resp. the linear functional)

$$
\left\{\mathrm{q}, \mathrm{q}^{\prime}\right\} \rightarrow \int_{\Omega}(\mathrm{Aq}) \mathrm{q}^{\prime} \mathrm{dx}
$$

(resp.

$$
\left.\mathrm{q} \rightarrow-\int_{\Omega} \underset{\sim}{\nabla} \cdot \underline{\sim}_{0} \mathrm{q} \mathrm{dx}\right)
$$

is continuous, H-elliptic and symmetric (resp. continuous) (the H-ellipticity means that there exists $\gamma>0$ such that

$$
\left.\int_{\Omega}(\mathrm{Aq}) \mathrm{q} \mathrm{dx} \geq \gamma\|\mathrm{q}\|_{\mathrm{L}^{2}(\Omega)}^{2}, \quad \forall \mathrm{q} \in \mathrm{H}\right)
$$


6.3. Conjugate gradient solution of linear variational problems.

Problem (6.10) is a particular case of

$$
\left\{\begin{array}{c}
\text { Find } \mathrm{u} \in \mathrm{V} \text { such that } \\
\mathrm{a}(\mathrm{u}, \mathrm{v})=\mathrm{L}(\mathrm{v}), \forall \mathrm{v} \in \mathrm{V}
\end{array}\right.
$$

where $\mathrm{V}$ is a real Hilbert space for the scalar product $(\cdot, \cdot)$ and the corresponding norm $\|\cdot\|$; where $\mathrm{a}(\cdot, \cdot)$ (resp. L) is a bilinear, continuous, symmetric and V-elliptic functional (resp. a linear continuous functional) defined over $\mathrm{V} \times \mathrm{V}$ (resp. V). From the Lax-Milgram lemma (see, e.g. [4, Appendix 1]) problem (6.11) has a unique solution. To compute $u$ we can use the following conjugate gradient algorithm:

Step 0: Initialization.

$$
\mathrm{u}^{0} \in \mathrm{V}, \text { given }
$$

solve then

$$
\left\{\begin{array}{l}
\mathrm{g}^{0} \in \mathrm{V}, \\
\left(\mathrm{g}^{0}, \mathrm{v}\right)=\mathrm{a}\left(\mathrm{u}^{0}, \mathrm{v}\right)-\mathrm{L}(\mathrm{v}), \forall \mathrm{v} \in \mathrm{V},
\end{array}\right.
$$

and set

$$
\mathrm{w}^{0}=\mathrm{g}^{0} .
$$

Then for $\mathrm{n} \geq 0$, assuming that $\mathrm{u}^{\mathrm{n}}, \mathrm{g}^{\mathrm{n}}, \mathrm{w}^{\mathrm{n}}$ are known compute $\mathrm{u}^{n+1}$, as follows:

Step 1: Descent

\section{Compute}

$$
\rho_{\mathrm{n}}=\frac{\left\|\mathrm{g}^{\mathrm{n}}\right\|^{2}}{\mathrm{a}\left(\mathrm{w}^{\mathrm{n}}, \mathrm{w}^{\mathrm{n}}\right)}
$$


and then

$$
u^{n+1}=u^{n}-\rho_{n} w^{n} .
$$

Step 2: Testing the convergence and updating the new descent direction.

Solve

$$
\left\{\begin{array}{l}
\mathrm{g}^{\mathrm{n}+1} \in \mathrm{V}, \\
\left(\mathrm{g}^{\mathrm{n}+1}, \mathrm{v}\right)=\left(\mathrm{g}^{\mathrm{n}}, \mathrm{v}\right)-\rho_{\mathrm{n}} \mathrm{a}\left(\mathrm{w}^{\mathrm{n}}, \mathrm{v}\right), \forall \mathrm{v} \in \mathrm{V} .
\end{array}\right.
$$

If

$$
\left\|\mathrm{g}^{\mathrm{n}+1}\right\| /\left\|\mathrm{g}^{\mathrm{o}}\right\| \leq \epsilon
$$

take $\mathrm{u}=\mathrm{u}^{\mathrm{n}}$; if not compute

$$
\gamma_{n}=\frac{\left\|g^{n+1}\right\|^{2}}{\left\|g^{n}\right\|^{2}}
$$

and update then $\mathrm{w}^{\mathrm{n}}$ by

$$
\mathrm{w}^{\mathrm{n}+1}=\mathrm{g}^{\mathrm{n}+1}+\gamma_{\mathrm{n}} \mathrm{w}^{\mathrm{n}}
$$

Do $\mathrm{n}=\mathrm{n}+1$ and go to $(6.15)$.

For finite dimensional problems (6.11) (for which algorithm $(6.12)-(6.20)$ is nothing but a preconditioned conjugate gradient algorithm for solving a linear problem), we have been quite successful, taking $\epsilon=10^{-7}$ in (6.18), when running on the CRAY-XMP.

Concerning the speed of convergence, it can be shown that 


$$
\left\|u^{n+1}-u\right\| \leq c\left\|u^{0}-u\right\|\left(\frac{\sqrt{\gamma_{a}}-1}{\sqrt{\gamma_{a}}+1}\right)^{n}
$$

where the condition number $\gamma_{\mathrm{a}}$ of $\mathrm{a}(\cdot, \cdot)$ is defined by

$$
\gamma_{a}=\frac{\operatorname{Sup}_{v \in V-\{0\}} \frac{a(v, v)}{\|v\|^{2}}}{\operatorname{Inf}_{v \in V-\{0\}} \frac{a(v, v)}{\|v\|^{2}}} .
$$

6.4. Selecting the right scalar product over $\mathrm{H}$.

Back to problem (6.9), (6.10), which can be solved by algorithm (6.12) - (6.20), a very important issue is the right choice for the $\mathrm{H}$-scalar product. Indeed, the usual $\mathrm{L}^{2}$-scalar product, i.e.

$$
\left\{\mathrm{q}, \mathrm{q}^{\prime}\right\} \rightarrow \int_{\Omega} \mathrm{qq}^{\prime} \mathrm{dx},
$$

is not well suited for the solution of $(6.9),(6.10)$ by algorithm (6.12)-(6.20); a quasi optimal scalar product (cf., e.g., [20, chapt.3], and the references therein, for a justification) is provided by

$$
\left(\mathrm{q}, \mathrm{q}^{\prime}\right)_{\mathrm{H}}=\int_{\Omega}(\mathrm{Sq}) \mathrm{q}^{\prime} \mathrm{dx}
$$

where $\mathrm{S}$ is the self-adjoint and strongly elliptic operator from $\mathrm{H}$ onto itself, defined by

$$
\mathrm{S}^{-1} \mathrm{q}=\nu \mathrm{q}+\alpha \varphi_{\mathrm{q}}
$$

where $\varphi_{\mathrm{q}}$ is the unique solution in $\mathrm{H}^{1}(\Omega) \cap \mathrm{H}$ of the Neumann problem

$$
\left\{\begin{array}{l}
-\tilde{\nabla}^{2} \varphi_{\mathrm{q}}=\mathrm{q} \text { in } \Omega \\
\frac{\partial \varphi_{\mathrm{q}}}{\partial \mathrm{n}}=0 \text { on } \Gamma ; \int_{\Omega} \varphi_{\mathrm{q}} \mathrm{dx}=0
\end{array}\right.
$$

We observe that, $\forall \mathrm{q}, \mathrm{q}^{\prime} \in \mathrm{H}$, we have (with obvious notation) 


$$
\int_{\Omega}\left(\mathrm{S}^{-1} \mathrm{q}\right) \mathrm{q}^{\prime} \mathrm{dx}=\nu \int_{\Omega} \mathrm{qq}^{\prime} \mathrm{dx}+\alpha \int_{\Omega} \underset{\sim}{\nabla} \boldsymbol{\varphi} \mathrm{q} \cdot \underset{\sim}{\nabla} \mathrm{q}^{\prime}, \mathrm{dx}
$$

which clearly implies that $\mathrm{S}^{-1}$ (and therefore $\mathrm{S}$ ) is self-adjoint and strongly elliptic over $\mathrm{H}$.

6.5 Conjugate gradient solution of problem (6.9), (6.10).

Applying algorithm (6.12) - (6.20) to the solution of the pressure equation (6.9), (6.10) (using as scalar product over $\mathrm{H}$ the one defined by $(6.21)$ - (6.23)) we obtain the following algorithm, which is also an iterative method for solving the quasi-Stokes problem (6.1):

$$
\mathrm{p}^{0} \in \mathrm{L}^{2}(\Omega), \text { given; }
$$

solve the Dirichlet system

$$
\left\{\begin{array}{c}
\alpha{\underset{\sim}{u}}^{0}-\nu \underset{\sim}{\nabla}{\underset{\sim}{u}}^{0}=\underset{\sim}{f}-\underset{\sim}{\nabla} p^{0} \text { in } \Omega, \\
\underline{\sim}^{0}=\underset{\sim}{g} \text { on } \Gamma
\end{array}\right.
$$

and the Neumann problem

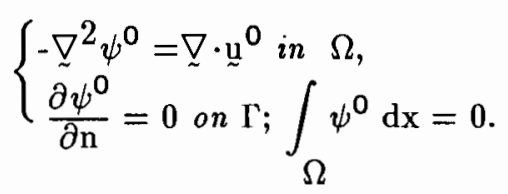

Set then

$$
\mathbf{g}^{0}=\nu \underset{\sim}{\nabla} \cdot \underline{\sim}^{0}+\alpha \psi^{0}
$$

and

$$
\mathrm{w}^{0}=\mathrm{g}^{0}
$$

Then for $\mathrm{n} \geq 0$, assuming that $\mathrm{p}^{\mathrm{n}}, \underset{\sim}{\mathrm{n}}, \mathrm{g}^{\mathrm{n}}, \mathrm{w}^{\mathrm{n}}$ are known, we obtain $\mathrm{p}^{\mathrm{n}+1}, \underset{\sim}{\mathrm{u}+1}, \mathrm{~g}^{\mathrm{n}+1}$, 
$\mathrm{w}^{\mathrm{n}+1}$ as follows:

Solve the Dirichlet system:

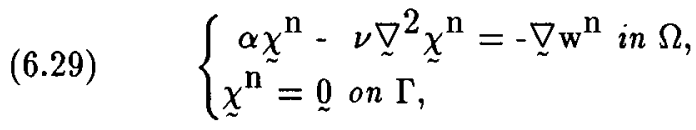

and compute

$$
\rho_{\mathrm{n}}=\frac{\int_{\Omega}^{\underset{\sim}{\nabla} \cdot \underset{\sim}{\mathrm{u}} \mathrm{g}^{\mathrm{n}} \mathrm{dx}}}{\int_{\Omega}^{\underset{\sim}{\nabla}} \underset{\sim}{\mathrm{n}_{\mathrm{w}}^{\mathrm{n}} \mathrm{dx}}}
$$

$$
\begin{aligned}
& \mathrm{p}^{\mathrm{n}+1}=\mathrm{p}^{\mathrm{n}}-\rho_{\mathrm{n}} \mathrm{w}^{\mathrm{n}} \\
& \mathrm{u}^{\mathrm{n}+1}={\underset{\sim}{\mathrm{u}}}^{\mathrm{n}}-\rho_{\mathrm{n}}{\underset{\sim}{\chi}}^{\mathrm{n}} .
\end{aligned}
$$

Solve now the Neumann problem

(6.33) $\quad\left\{\begin{array}{l}-{\underset{\sim}{2}}^{2} \varphi^{\mathrm{n}}=\underset{\sim}{\nabla} \cdot{\underset{\sim}{\chi}}^{\mathrm{n}} \text { in } \Omega \\ \frac{\partial \varphi^{\mathrm{n}}}{\partial \mathrm{n}}=0 \text { on } \Gamma ; \int_{\Omega} \varphi^{\mathrm{n}} \mathrm{d} \mathbf{x}=0\end{array}\right.$

and compute

$$
\mathrm{g}^{\mathrm{n}+1}=\mathrm{g}^{\mathrm{n}}-\rho_{\mathrm{n}}\left(\nu \underset{\sim}{\nabla} \cdot{\underset{\sim}{\mathrm{n}}}^{\mathrm{n}}+\alpha \varphi^{\mathrm{n}}\right) .
$$

If

$$
\frac{\int_{\Omega}^{\underset{\sim}{\nabla} \cdot \stackrel{\sim}{u}^{n+1} g^{n+1} \mathrm{dx}}}{\int_{\Omega}^{\nabla} \underset{\sim}{u_{0}^{0}} \mathrm{~g}^{0} \mathrm{dx}} \leq \epsilon
$$


take

$$
\mathrm{p}=\mathrm{p}^{\mathrm{n}+1}, \underset{\sim}{\mathrm{u}}={\underset{\sim}{\mathrm{u}}}^{\mathrm{n}+1} .
$$

If (6.35) does not hold, compute

$$
\gamma_{\mathrm{n}}=\frac{\int_{\Omega}^{\underset{\sim}{\nabla} \cdot{\underset{\sim}{u}}^{\mathrm{n}+1} \mathrm{~g}^{\mathrm{n}+1} \mathrm{dx}}}{\int_{\Omega}^{\underset{\sim}{\nabla} \cdot \underline{\sim}^{\mathrm{n}} \mathrm{g}^{\mathrm{n}} \mathrm{dx}}},
$$

and set

$$
w^{n+1}=g^{n+1}+\gamma_{n} w^{n} .
$$

Do $\mathrm{n}=\mathrm{n}+1$ and go to $(6.29)$.

Numerical experiments show that the above algorithm behaves quite uniformly for a wide range of values of $\alpha$ and $\nu$; in practice 4 to 5 iterations will be sufficient to obtain good approximations of $\underset{\sim}{\mathrm{u}}$ and $\mathrm{p}$. We observe also that each iteration requires the solution of a Dirichlet system $((6.25)$ or (6.29)) and of a Neumann problem $((6.26)$ or (6.33)). As we shall see in Section 7 , for flows at large Reynold numbers, for which $\nu$ is small and $\alpha(\sim 1 / \Delta \mathrm{t})$ is large, solving the discrete variants of (6.25) and (6.29) is easy, since the matrix approximating $\alpha \mathrm{I}-\nu{\underset{\sim}{2}}^{2}$ will be very well conditioned; on the other hand the Neumann problems (6.26) and (6.33) do not enjoy these good properties and their practical solution still deserves further investigations; multigrid methods (geometric or algebraic) are interesting candidates to provide efficient Neumann solvers.

As a last comment, we would like to observe that algorithm $(6.24)-(6.38)$ converges even if $\mathrm{p}^{0} \notin \mathrm{H}$; in this case we shall have 


$$
\left\{\stackrel{\sim}{u}^{n}, p^{n}\right\} \rightarrow\{\underset{\sim}{u}, p\}
$$

where $\{\underset{\sim}{u}, p\}$ is the solution of $(6.1)$ such that

$$
\int_{\Omega} p d x=\int_{\Omega} p^{0} d x
$$

7. Finite Element Approximation of the Navier-Stokes Equations.

We shall describe in this section a specific class of finite element approximations for the time dependent Navier-Stokes equations. Actually these methods, which lead to continuous approximations for both pressure and velocity, are fairly simple and some of them have been known for years (cf. Hood and Taylor [21]). Other finite element approximations of the incompressible Navier-Stokes equations can be found in, e.g. , references [4], [5], [11], [22] (see also the references therein).

The two fundamental references (in our opinion) concerning the convergence of the fully discrete Navier-Stokes equations (finite elements in space, finite differences in time) are [23], [24].

\subsection{Basic hypotheses. Fundamental discrete spaces.}

We suppose that $\Omega$ is a bounded polygonal domain of $\mathbb{R}^{2}$. With $\mathcal{T}_{h}$ a standard finite element triangulation of $\Omega$, and $h$ the maximal length of the edges of the triangles of $\sigma_{h}$, we introduce the following discrete spaces (with $\mathrm{P}_{\mathrm{k}}=$ space of the polynomials in two variables of degree $\leq \mathrm{k}$ ):

$$
\begin{aligned}
& \mathrm{H}_{h}^{1}=\left\{\mathrm{q}_{h}\left|\mathrm{q}_{h} \in \mathrm{C}^{0}(\bar{\Omega}), \mathrm{q}_{h}\right|_{\mathrm{T}} \in \mathrm{P}_{1}, \forall \mathrm{T} \in \mathcal{T}_{h}\right\}, \\
& \mathrm{v}_{h}=\left\{\underline{\mathrm{v}}_{h}\left|\underline{\mathrm{v}}_{h} \in \mathrm{C}^{0}(\bar{\Omega}) \times \mathrm{C}^{0}(\bar{\Omega}), \underline{\sim}_{h}\right|_{\mathrm{T}} \in \mathrm{P}_{2} \times \mathrm{P}_{2}, \forall \mathrm{T} \in \mathcal{T}_{h}\right\}, \\
& \mathrm{v}_{0 h}=\left\{\underline{v}_{h} \mid \mathrm{v}_{h} \in \mathrm{v}_{h}, \underline{v}_{h}=\underset{\sim}{\text { on } \Gamma}\right\}=\mathrm{v}_{h} \cap\left(\mathrm{H}_{0}^{1}(\Omega)\right)^{2} .
\end{aligned}
$$


Two useful variants of $\mathrm{V}_{h}$ (and $\mathrm{V}_{\mathrm{oh}}$ ) are obtained as follows: either

$$
\mathrm{V}_{h}=\left\{\underline{\mathrm{v}}_{h}\left|\mathrm{v}_{h} \in \mathrm{C}^{0}(\bar{\Omega}) \times \mathrm{C}^{0}(\bar{\Omega}), \underline{\mathrm{v}}_{h}\right|_{\mathrm{T}} \in \mathrm{P}_{1} \times \mathrm{P}_{1}, \forall \mathrm{T} \in \tilde{\boldsymbol{\sigma}}_{h}\right\}
$$

or (this space has been introduced in [25])

$$
\mathrm{V}_{h}=\left\{\underline{v}_{h}\left|\mathbf{v}_{h} \in \mathrm{C}^{0}(\bar{\Omega}) \times \mathrm{C}^{0}(\bar{\Omega}), \underline{\mathbf{v}}_{h}\right|_{\mathrm{T}} \in \mathrm{P}_{1 \mathrm{~T}}^{*} \times \mathrm{P}_{1 \mathrm{~T}}^{*}, \forall \mathrm{T} \in \mathrm{T}_{h}\right\}
$$

In (7.4), $\tilde{\mathcal{T}}_{h}$ is the triangulation of $\Omega$ obtained from $\mathscr{T}_{h}$ by joining the midpoints of the edges of $T \in \mathcal{T}_{h}$, as shown in Fig. 7.1. We have the

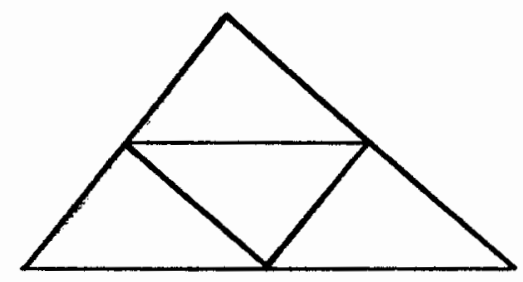

Figure 7.1

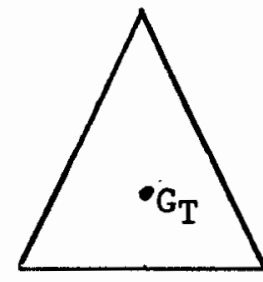

Figure 7.2

same global number of unknowns if we use $V_{h}$ defined by either (7.2) or (7.4), however, the matrices encountered in the second case are more compact and sparse and also better conditioned.

In (7.5), $\mathrm{P}_{1 \mathrm{~T}}^{*}$ is the subspace of $\mathrm{P}_{3}$ defined as follows

$$
\left\{\begin{array}{l}
\mathrm{P}_{1 \mathrm{~T}}^{*}=\left\{\mathrm{q} \mid \mathrm{q}=\mathrm{q}_{1}+\lambda \varphi_{\mathrm{T}}, \text { with } \mathrm{q}_{1} \in \mathrm{P}_{1}, \lambda \in R\right. \\
\text { and } \left.\varphi_{\mathrm{T}} \in \mathrm{P}_{3}, \varphi_{\mathrm{T}}=0 \text { on } \partial \mathrm{T}, \varphi_{\mathrm{T}}\left(\mathrm{G}_{\mathrm{T}}\right)=1\right\}
\end{array}\right.
$$

where, in (7.6), $\mathrm{G}_{\mathrm{T}}$ is the centroid of $\mathrm{T}$ (see Figure 7.2). A function like $\varphi_{\mathrm{T}}$ is usually called a bubble function.

\subsection{Approximation of the boundary conditions.}

If the boundary conditions are defined by 


$$
\underline{\mathrm{u}}=\underset{\sim}{\mathrm{g}} \text { on } \Gamma, \int_{\Gamma}^{\mathrm{g}} \cdot \underset{\sim}{\mathrm{n}} \mathrm{d} \Gamma=0,
$$

it is of fundamental importance to approximate $\mathrm{g}_{\sim}$ by $\underset{\sim}{\mathrm{g}}$ such that

$$
\int_{\Gamma} \underset{\sim}{\mathrm{g}_{h}} \cdot \underset{\sim}{\mathrm{n}} \mathrm{d} \Gamma=0
$$

Let's discuss the construction of such a $\mathrm{g}_{h}$ (we follow here [4, Appendix 3]). For simplicity, we shall suppose that $\mathrm{g}$ is continuous over $\Gamma$. We now define the space $\gamma \mathrm{V}_{h}$ as

$$
\gamma \mathrm{V}_{h}=\left\{\left.\underset{\sim}{\mu}{\underset{\sim}{\mu} h}_{\boldsymbol{x}_{h}}\right|_{\Gamma}, \underline{\sim}_{h} \in \mathrm{v}_{h}\right\},
$$

i.e. $\gamma \mathrm{V}_{h}$ is the space of the traces on $\Gamma$ of those functions $\underline{v}_{h}$ belonging to $\mathrm{V}_{h}$. Actually, if $\mathrm{V}_{h}$ is defined by (7.2), $\gamma \mathrm{V}_{h}$ is also the space of those functions defined over $\Gamma$, taking their values in $\mathbb{R}^{2}$, continuous over $\Gamma$ and piecewise quadratic over the edges of $\sigma_{h}$ contained in $\Gamma$.

Our problem is to construct an approximation $\mathrm{g}_{h}$ of $\underset{\sim}{\mathrm{g}}$ such that

$$
\underset{\sim}{\mathrm{g}_{h}} \in \gamma \mathrm{v}_{h}, \int_{\Gamma} \underset{\mathrm{g}_{h}}{ } \cdot \underset{\sim}{\mathrm{n}} \mathrm{d} \Gamma=0 .
$$

If $\pi_{h} \mathrm{~g}$ is the unique element of $\gamma \mathrm{V}_{h}$, obtained by piecewise quadratic interpolation of $\underset{\sim}{\mathrm{g}}$ over $\Gamma$, i.e. obtained from the values taken by $g_{\sim}$ at those nodes of $\mathcal{T}_{h}$ belonging to $\Gamma$, we usually have

$\int_{\Gamma} \pi_{h} \mathrm{~g} \cdot \underset{\sim}{\mathrm{n}} \mathrm{d} \Gamma \neq 0$. To overcome this difficulty, we may proceed as follows:

(i) We define an approximation $\underset{\sim}{\mathfrak{n}} h$ of $\underset{\sim}{\mathrm{n}}$ as the solution of the following linear variational problem in $\gamma \mathrm{V}_{h}$ :

$$
\stackrel{\sim}{\mathrm{n}}_{h} \in \gamma \mathrm{V}_{h}, \int_{\Gamma} \underset{\sim}{\mathrm{n}_{h}} \stackrel{\mu}{\mu} h_{h} \mathrm{~d} \Gamma=\int_{\Gamma} \underset{\sim}{\mathrm{n}} \cdot \underset{\sim}{\mu} \mathrm{d} \Gamma, \forall \underset{\sim}{\mu} \in \gamma \mathrm{V}_{h} .
$$

Problem (7.11) is in fact equivalent to a linear system whose matrix is sparse, symmetric, positive 
definite, well-conditioned and easy to compute.

(ii) Define ${\underset{\sim}{h}}_{h}$ by

$$
{\underset{\sim}{\mathrm{g}}}_{h}=\pi_{h} \underset{\sim}{\mathrm{g}}-\left(\int_{\Gamma}{\underset{\sim}{h}}_{h} \underset{\sim}{\mathrm{g}} \cdot \underset{\sim}{\mathrm{n}} \mathrm{d} \Gamma / \int_{\Gamma}^{\mathrm{n}} \underset{\sim}{\mathrm{n}} \underset{h}{\mathrm{n}} \mathrm{d} \Gamma\right)_{\sim}^{\mathrm{n}} h .
$$

It is easy to check that (7.11), (7.12) imply (7.10).

7.4 Space approximation of the time dependent Navier-Stokes equations.

Using the spaces $\mathrm{H}_{h}^{1}, \mathrm{~V}_{h}$ and $\mathrm{V}_{\mathrm{o}}$, we approximate the time dependent Navier-Stokes equations as follows.

Find $\left\{\underline{\mathrm{u}}_{h}(\mathrm{t}), \mathrm{p}_{h}(\mathrm{t})\right\} \in \mathrm{V}_{h} \times \mathrm{H}_{h}^{1}, \forall \mathrm{t} \geq 0$, such that

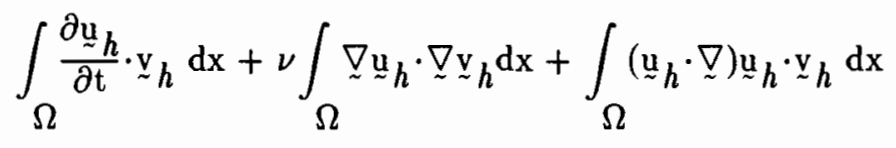

$$
+\int_{\Omega} \underset{\sim}{\nabla} \mathbf{p}_{h} \cdot \underline{v}_{h} \mathrm{dx}=\int_{\Omega} \mathfrak{f}_{h} \cdot \mathfrak{v}_{h} \mathrm{dx}, \forall \mathfrak{v}_{h} \in \mathrm{V}_{0 h},
$$

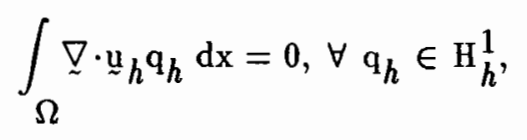

$$
\stackrel{\mathrm{u}}{h}_{h}=\mathrm{g}_{h} \text { on } \Gamma,
$$

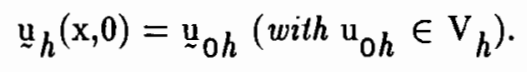

In (7.13) - (7.16), $\underset{\sim}{\mathrm{f}}, \stackrel{\sim}{\mathrm{u}}_{0 h}$ and ${\underset{\sim}{\mathrm{g}} h}_{h}$ are convenient approximations of $\underset{\sim}{\mathrm{f}},{\underset{\sim}{0}}_{0}$ and $\underset{\sim}{\mathrm{g}}$, respectively. 


\subsection{Time discretization by operator splitting methods.}

We consider now a fully discrete version of scheme (4.1) - (4.4), discussed in Section 4. It is defined as follows (with $\Delta \mathrm{t}$ as in Section 4.):

$$
\underline{\sim}_{h}^{0}=\underline{\sim}_{0 h} ;
$$

then for $\mathrm{n} \geq 0$, compute $\left(\right.$ from $\left.\underline{\sim}_{h}^{\mathrm{n}}\right)\left\{{\underset{\sim}{\alpha}}_{h}^{\mathrm{n}+\theta}, \mathrm{p}_{h}^{\mathrm{n}+\theta}\right\} \in \mathrm{V}_{h} \times \mathrm{H}_{h}^{1}$, then ${\underset{\sim}{\mathrm{u}}}_{h}^{\mathrm{n}+1-\theta} \in \mathrm{V}_{h}$, and finally

$\left\{\stackrel{\mathrm{u}}{\mathrm{u}}_{h}^{\mathrm{n}+1}, \mathrm{p}_{h}^{\mathrm{n}+1}\right\} \in \mathrm{V}_{h} \times \mathrm{H}_{h}^{1}$ by solving

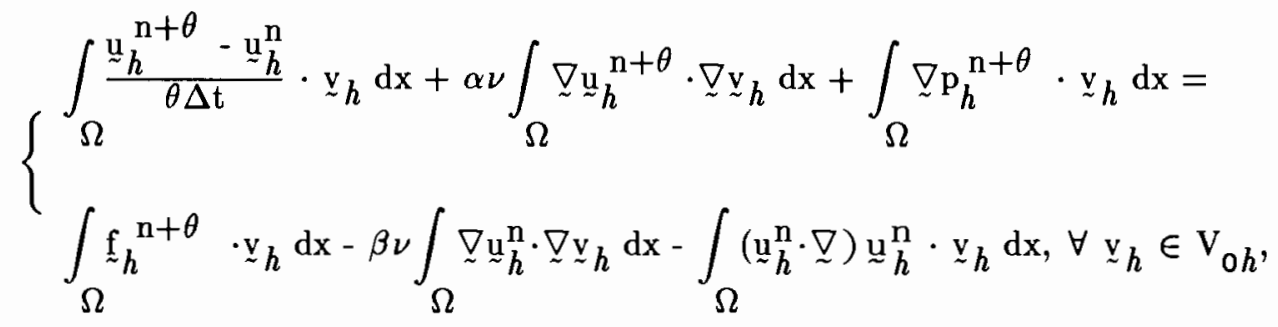

$(7.18)_{2} \quad \int_{\Omega} \underset{\sim}{\nabla} \cdot \underline{\sim}_{h}^{\mathrm{u}}{ }^{\mathrm{n}+\theta} \mathrm{q}_{h} \mathrm{dx}=0, \forall \mathrm{q}_{h} \in \mathrm{H}_{h}^{1}$,

$$
(7.18)_{3} \quad \underline{\sim}_{h}^{\mathrm{n}+\theta} \in \mathrm{V}_{h}, \mathrm{p}_{h}^{\mathrm{n}+\theta} \in \mathrm{H}_{h}^{1}, \stackrel{\mathrm{u}}{h}_{h}^{\mathrm{n}+\theta}=\mathrm{g}_{h}^{\mathrm{n}+\theta} \text { on } \Gamma
$$

then

$$
\int_{\Omega}^{{\underset{\sim}{u}}_{h}^{\mathrm{n}+1-\theta}-\underline{\sim}_{h}^{\mathrm{n}+\theta}} \cdot \underline{\sim}_{h} \mathrm{dx}+\beta \nu \int_{\Omega}{\underset{\sim}{\nabla}}_{h}^{\mathrm{u}}{ }^{\mathrm{n}+1-\theta} \cdot \underline{\sim}_{\mathrm{v}_{h}} \mathrm{dx}
$$

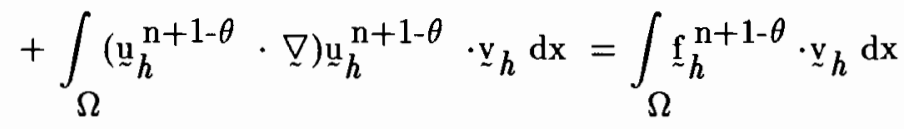




$$
-\alpha \nu \int_{\Omega} \underset{\sim}{\nabla} \sim_{h}^{\mathrm{n}+\theta} \cdot \sim_{h}^{\mathrm{v}} \mathrm{dx}-\int_{\Omega} \underset{\sim}{\nabla} \mathrm{p}_{h}^{\mathrm{n}+\theta} \cdot \sim_{h}^{\mathrm{v}} \mathrm{dx}, \forall{\underset{\sim}{\mathrm{v}}}_{h} \in \mathrm{V}_{\mathrm{o} h}
$$

$(7.19)_{2} \quad \stackrel{\sim}{\mathrm{u}}_{h}^{\mathrm{n}+1-\theta} \in \mathrm{V}_{h}, \stackrel{\sim}{\mathrm{u}}_{h}^{\mathrm{n}+1-\theta}=\mathrm{g}_{h}^{\mathrm{n}+1-\theta}$ on $\Gamma$,

and finally

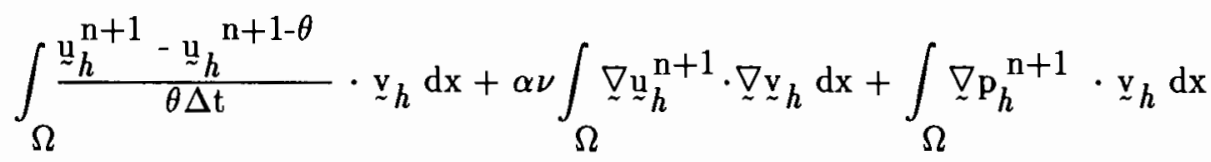

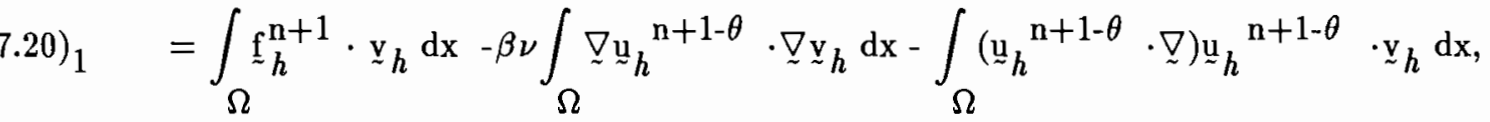

$$
\forall \underline{\mathrm{v}}_{h} \in \mathrm{V}_{\mathrm{oh}}
$$

$$
\int_{\Omega} \underset{\sim}{\nabla} \cdot \stackrel{\mathrm{u}}{\mathrm{u}}_{h}^{\mathrm{n}+1} \mathrm{q}_{h} \mathrm{dx}=0, \forall \mathrm{q}_{h} \in \mathrm{H}_{h}^{1}
$$

$$
{\underset{\sim}{\mathrm{u}}}_{h}^{\mathrm{n}+1} \in \mathrm{v}_{h}, \mathrm{p}_{h}^{\mathrm{n}+1} \in \mathrm{H}_{h}^{1}, \stackrel{\mathrm{u}}{\mathrm{u}}_{h}^{\mathrm{n}+1}={\underset{\sim}{h}}_{h}^{\mathrm{n}+1} \text { on } \Gamma,
$$

respectively.

We shall take again $\alpha=(1-2 \theta) /(1-\theta), \beta=\theta /(1-\theta)$.

\subsection{Remarks concerning the computer solution of the discrete problems.}

The solution of the subproblems encountered at each step of (7.17) - (7.20) can be obtained by iterative methods which are the discrete analogues of the methods discussed in Sections 5 and 6 . In particular, we shall have to solve quite systematically linear systems approximating Dirichlet problems of the following type: 


$$
\left\{\begin{array}{l}
\alpha \underset{\sim}{u}-\nu \underset{\sim}{\nabla}{ }^{2} \underset{\sim}{u}=\underset{\sim}{\mathrm{f}} \text { in } \Omega \\
\underline{\sim} \text { on }
\end{array}\right.
$$

Paradoxically, solving (7.21) is not very expensive for flows at high Reynold numbers. For such flows the viscosity $\nu$ is small and their fast dynamics requires small $\Delta$ t, i.e., large values of $\alpha$. Suppose for simplicity that $\Omega=(0,1)^{2}$ and also that one uses over $\Omega$ a regular triangulation like the one in Figure 7.3 , where $h=1 /(\mathrm{N}+1)(\mathrm{N}$ a positive integer).

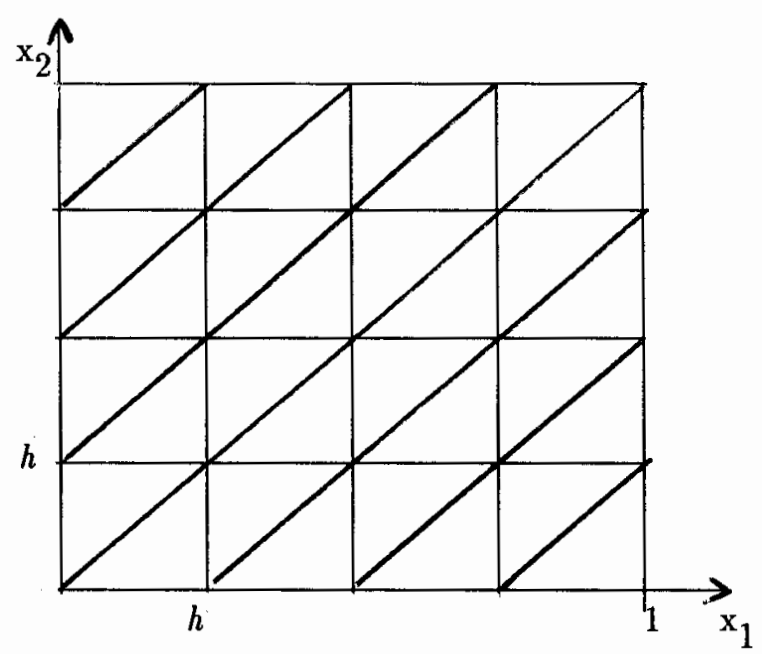

Figure 7.3

Suppose also that one uses continuous and piecewise linear approximations of the velocity over the above triangulation and that integrals like $\int_{\Omega} \underset{\sim}{\mathrm{v}} \cdot \underset{\sim}{\mathrm{w}} \mathrm{dx}$ are approximated using the trapezoidal rule. One obtains then the approximation of (7.21) associated to a traditional five point formula, i.e. (with obvious notation)

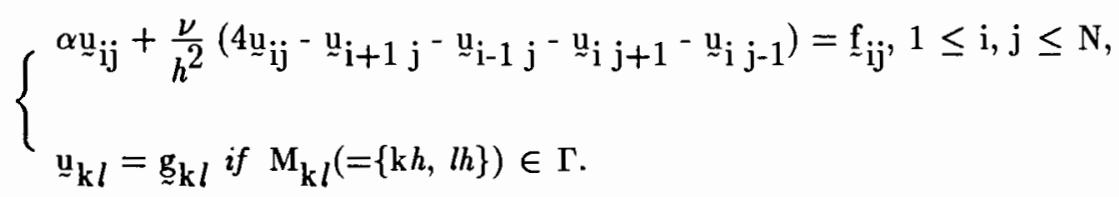

It is well known that the matrix in (7.22) has for smallest and largest eigenvalues 


$$
\lambda_{\min }=\alpha+\frac{8 \nu}{h^{2}} \sin ^{2} \frac{\pi h}{2}
$$

and

$$
\lambda_{\max }=\alpha+\frac{8 \nu}{h^{2}} \sin ^{2} \frac{\mathrm{N} \pi h}{2}
$$

respectively. For small values of $h$, we clearly have

$$
\begin{aligned}
& \lambda_{\min } \sim \alpha+2 \pi^{2} \nu \\
& \lambda_{\max } \sim \alpha+\frac{8 \nu}{h^{2}}
\end{aligned}
$$

implying for the condition number $\mathcal{N}$ of the above matrix

$$
\mathcal{N}=\frac{\lambda_{\max }}{\lambda_{\min }} \sim\left(\alpha+\frac{8 \nu}{h^{2}}\right) /\left(\alpha+2 \pi^{2} \nu\right)
$$

Suppose now that $\nu=10^{-3}, h=10^{-2}, \Delta \mathrm{t}=10^{-2}\left(\Rightarrow \alpha=10^{2}\right)$, we have then

$$
\mathcal{N} \sim 1.8
$$

Suppose now that we solve the linear system (7.22) by a nonpreconditoned conjugate gradient algorithm. It follows then from (7.26) and from Section 6.3 that the distance between the solution of (7.22) and the $\mathrm{n}^{\text {th }}$ iterate converges to zero at least as fast as

$$
\left(\frac{\sqrt{1.8}-1}{\sqrt{1.8}+1}\right)^{\mathrm{n}}=(.145898 \ldots . .)^{\mathrm{n}}
$$

which corresponds to a quite high speed of convergence. A similar conclusion would hold for successive over-relaxation with optimal parameter. Actually, the convergence of the above methods is so fast that speeding up by a multi-grid method would be useless. Indeed, the above methods are quite simple and are fairly easy to vectorize. The above observation holds for the problems of type (7.22) encountered in the solution of the linear steps (7.18), (7.20) and of the nonlinear step (7.19). Concentrating on the 
discrete quasi-Stokes problems (7.18), (7.20), their solution by a variant of algorithm (6.24) - (6.38) requires at each iteration the solution of a linear system approximating a Neumann problem of the following type

$$
\left\{\begin{array}{l}
-\nabla^{2} \varphi=\mathrm{f} \text { in } \Omega \\
\frac{\partial \tilde{\varphi}}{\partial \mathrm{n}}=0 \text { on } \Gamma ; \int_{\Omega} \varphi \mathrm{dx}=0
\end{array}\right.
$$

(with $\int \mathrm{f} d \mathrm{x}=0$ ). The matrix approximating the Neumann-Laplace operator occuring in (7.27) does not enjoy the nice properties of $\alpha \mathrm{I}-\nu \nabla^{2}$ and therefore the approximate solution of (7.27) may be costly. At the moment we use a direct method (à la Cholesky) for solving these discrete Neumann problems (after deleting one equation and setting to zero the corresponding unknown). As already mentioned, the above strategy may seem costly. We have however to remember that the above discrete Neumann problems have to be solved in the pressure space $\mathrm{H}_{h}^{1}$ and therefore correspond to a grid twice coarser than the velocity grid. Nevertheless, in view of three-dimensional flow problems, we are now considering multigrid approaches for the solution of these discrete Neumann problems.

\section{Numerical experiments.}

Combining the numerical methods described in the above sections we have been considering the following test problem (double jet in square cavity; this problem was inspired to us by the Kowasznay lecture, given by W. C. Reynold in 1987 at the University of Houston).

Here $\Omega=(0,1) \times(0,1), \nu=1 / 8000$ and the boundary conditions are the following:

$$
\begin{aligned}
& \underset{\sim}{\mathrm{g}}\left(\mathrm{x}_{1}, \mathrm{x}_{2}\right)=\underset{\sim}{0} \text { if } \mathrm{x}_{1}=0 \text { or } 1 \\
& \underset{\sim}{\mathrm{g}\left(\mathrm{x}_{1}, 1\right)=0} \text { if } 0 \leq \mathrm{x}_{1} \leq \frac{1}{3}, \frac{19}{48} \leq \mathrm{x}_{1} \leq \frac{29}{48}, \frac{2}{3} \leq \mathrm{x}_{1} \leq 1 \\
& \underset{\sim}{\mathrm{g}\left(\mathrm{x}_{1}, 1\right)=-1024}\left\{\frac{1}{\sqrt{2}}, \frac{1}{\sqrt{2}}\right\}\left(\mathrm{x}_{1}-\frac{1}{3}\right)\left(\frac{19}{48}-\mathrm{x}_{1}\right) \text { if } \frac{1}{3} \leq \mathrm{x}_{1} \leq \frac{19}{48}\left(=\frac{1}{3}+\frac{1}{16}\right)
\end{aligned}
$$




$$
\underset{\sim}{\mathrm{g}}\left(\mathrm{x}_{1}, 1\right)=1024\left\{\frac{1}{\sqrt{2}},-\frac{1}{\sqrt{2}}\right\}\left(\frac{2}{3}-\mathrm{x}_{1}\right)\left(\mathrm{x}_{1}-\frac{29}{48}\right) \text { if } \frac{29}{48}\left(=\frac{2}{3}-\frac{1}{16}\right) \leq \mathrm{x}_{1} \leq \frac{2}{3}
$$

$$
\mathrm{g}\left(\mathrm{x}_{1}, 0\right)=\underset{\sim}{0} \text { if } \frac{1}{16} \leq \mathrm{x}_{1} \leq \frac{15}{16}
$$

$$
\begin{aligned}
& \underset{\sim}{\mathrm{g}}\left(\mathrm{x}_{1}, 0\right)=-1024\left\{0, \frac{1}{\sqrt{2}}\right\} \mathrm{x}_{1}\left(\frac{1}{16}-\mathrm{x}_{1}\right) \text { if } 0 \leq \mathrm{x}_{1} \leq \frac{1}{16} \\
& \underset{\sim}{\mathrm{g}\left(\mathrm{x}_{1}, 0\right)}=-1024\left\{0, \frac{1}{\sqrt{2}}\right\}\left(1-\mathrm{x}_{1}\right)\left(\mathrm{x}_{1}-\frac{15}{16}\right) \text { if } \frac{15}{16} \leq \mathrm{x}_{1} \leq 1
\end{aligned}
$$

corresponding to injection of fluid by the upper apertures, and ejection by the lower ones.

From (8.1), we see that all apertures are $\frac{1}{16}$ wide, that the two jets' inclinations are $45^{\circ}$, the left (respectively right) one being oriented toward the left (respectively right) wall. We can also see that the maximum injection velocity is one. Parabolic profiles of velocity have been assumed at all the apertures.

Finally, we assume that the flow is initially at rest, i.e. $\underset{\sim}{\underset{1}{u}}(\mathrm{x}, 0)=\underset{\sim}{0}$ in $\Omega$.

From these characteristics, we can see that we actually need two Reynold numbers (at least) to characterize this jet problem; indeed, if one takes the dimension of the jet apertures as characteristic length, we clearly have $\operatorname{Re}=\frac{8000}{16}=500$, but if we consider the length of the cavity as another characteristic length, the corresponding Re is now 8000 (actually for the two upper corners we can also define a local Reynold number of $\frac{8000}{3}=2666.66 \ldots$, since $\frac{1}{3}$ is the distance of the upper apertures to the closest corner (and corresponding vertical wall)).

Our goal with these numerical experiments is to simulate the bouncing of the jets on the various walls, and to observe the evolution of the vortex pattern by visualization of the streamlines and of the vorticity contours at different values of $t$ (the streamlines have been defined as the contour lines of the stream function $\psi$, the solution of the Laplace equation

$$
-\nabla^{2} \psi=\omega \text { in } \Omega
$$


completed by adequate Dirichlet boundary conditions, with the vorticity $\omega$ defined by $\omega=\frac{\partial \mathrm{u}_{2}}{\partial \mathrm{x}_{1}}-\frac{\partial \mathrm{u}_{1}}{\partial \mathrm{x}_{2}}$ ).

Following Section 7, the velocity has been approximated by continuous functions, piecewise linear on a regular triangulation consisting of 80,000 triangles; the pressure has also been approximated by continuous and piecewise linear functions, but this time on a triangulation twice coarser than the velocity one. The total number of unknowns is then of the order of 80,000 for the velocity and 10,000 for the pressure. Concerning the time step, we have taken $\Delta t=10^{-2}$ and used the $\theta$-scheme (7.17) (7.20) with $\theta=1-\frac{1}{\sqrt{2}}$ and $\alpha, \beta$ given by (4.5).

We have shown in Figures 8.1 to 8.8 the streamlines and the vorticity contours corresponding to the computed solution at $\mathrm{t}=.5,1,1.5,2,2.5,3,11.5,13$, respectively. The evolution in time of the kinetic energy $\frac{1}{2} \int_{\Omega}|\underline{u}|^{2} \mathrm{dx}$ is shown on Figure 8.9. Numerical simulations done with smaller $\Delta \mathrm{t}$ give back the same results.

All these calculations have been done on a CRAY-XMP 201.

\section{Further Comments. Conclusions.}

We have discussed in this paper, a problem whose accurate solution - at least by the methods described here - requires supercomputing. The numerical results presented here have been obtained using a CRAY X-MP, taking benefit of the architecture of this vector machine. Indeed, the author is quite convinced that the level of vectorization of the various algorithms discussed here can be substantially increased, and he strongly hopes that the software tools for super and parallel computers developed at Rice University by K. Kennedy and his collaborators will allow his own collaborators and himself to take better advantage of the supercomputers used for the calculations described in the above sections, and to related calculations even more demanding (the three dimensional variants, for example).

Acknowledgement: The author would like to thank M. O. Bristeau, E. Dean, F. Hussain and J. Periaux, for helpful comments and suggestions concerning the scientific matters discussed here, and Denice McCormick and Sheridan Nassar for their beautiful processing of the manuscript of this paper. 


\section{REFERENCES}

[1] E. M. MURMAN, S.S. ABARBANEL eds. Progress and Supercomputing in Computational Fluid Dynamics, Birkhauser, Boston, (1985).

[2] R. GLOWINSKI, Viscous flow simulations by finite element methods and related numerical techniques, in Progress and Supercomputing in Computational Fluid Dynamics, E. M. Murman, S. S. Abarbanel eds., Birkhauser, Boston, (1985), pp. 173-210.

[3] M. O. BRISTEAU, R. GLOWINSKI, J. PERIAUX, Numerical Methods for the NavierStokes Equations, Computer Physics Reports 6, (1987), p.p. 73-187.

[4] R. GLOWINSKI, Numerical Methods for Nonlinear Variational Problems, Springer, New York, (1984).

[5] F. THOMASSET, Implementation of Finite Element Methods for Navier-Stokes Equations, Springer, New York, (1981).

[6] R. PEYRET, T.D. TAYLOR, Computational Methods for Fluid Flow, Springer, New York, (1982).

[7] O. A. LADYSENSKAYA, The Mathematical Theory of Viscous Incompressible Flows, Gordon and Breach, New York, (1969).

[8] J. L. LIONS, Quelques Methodes de Résolution des Problèmes aux Limites Non Linéaires, Dunod, Paris (1969).

[9] R. TEMAM, Navier-Stokes Equations, North-Holland, Amsterdam, (1977).

[10] L. TARTAR, Topics in Nonlinear Analysis, Université Paris-Sud, Département de Mathématiques, Paris, (1978).

[11] V. GIRAULT, P.A. RAVIART, Finite Element Methods for Navier-Stokes Equations, Springer, Berlin, (1986).

[12] M. O. BRISTEAU, R. GLOWINSKI, B. MANTEL, J. PERIAUX, P. PERRIER, Numerical Methods for Incompressible and Compressible Navier-Stokes Problems, in Finite Elements in Fluids, 6, R. H. Gallagher, G. Carey, J. T. Oden, O. C. Zienkiewicz eds., J. Wiley, Chichester, (1985), pp. 1-40.

[13] R. GLOWINSKI, Splitting Methods for the Numerical Solution of the Incompressible NavierStokes Equations, in Vistas in Applied Mathematics, A. V. Balakrishran, A. A. Doronitsyn, J. L. Lions eds., Optimization Software, New York, (1986), pp. 57-95. 
[14] E. DEAN, R. GLOWINSKI, C. H. LI, Application of Operator Splitting Methods to the Numerical Solution of Nonlinear Problems in Continuum Mechanics and Physics, in Mathematics Applied to Science, J. Goldstein, S. Rosencrans, G. Sod eds., Academic Press, Boston, (1988), pp. 13-64.

[15] E. DEAN, R. GLOWINSKI, C. H. LI, Numerical solution of the parabolic problems in high dimensions, in Transactions of the Fifth Army Conference on Applied Mathematics and Computing, ARO Report 88-1, pp. 207-285.

[16] G. I. MARCHUK, Methods of Numerical Mathematics, Springer, New York, (1975).

[17] R. GLOWINSKI, H. B. KELLER, L. REINHART, Continuation - Conjugate Gradient Methods for the Least Squares Solution of Nonlinear Boundary Value Problems, SIAM J. Sci. Stat. Comput. 6, (1985), 793.

[18] J. NECAS, Les Méthodes Directes en Théorie des Equations Elliptiques, Masson, Paris, (1967).

[19] R. A. ADAMS, Sobolev Spaces, Academic Press, New York, (1971).

[20] R. GLOWINSKI, P. LE TALLEC, Augmented Lagrangian Methods for the Solution of Variational Problems, MRC Report 2965, Mathematics Research Center, University of Wisconsin, Madison, (1987).

[21] P. HOOD, C. TAYLOR, A Numerical Solution of the Navier-Stokes Equations Using the Finite Element Technique, Computers and Fluids, 1, (1973), pp. 73-100.

[22] K. MORGAN, J. PERIAUX, F. THOMASSET eds., Numerical Analysis of Laminar Flow over a Step, Vieweg-Verlag, Braunschwerg, Wiesbaden, (1984).

[23] J. HEYWOOD, R. RANNACHER, Finite Element Approximation of the Nonstationary Navier-Stokes Problem (I): Regularity of Solutions and Second-Order Error Estimates for Spatial Discretization, SIAM J. Numer Anal. 19, (1982), 275.

[24] J. HEYWOOD, R. RANNACHER, Finite Element Approximation of the Nonstationary Navier-Stokes Problem (II): Stability of solutions and error estimates uniform in time, SIAM J. Numer. Anal 23, (1986), 750.

[25] D. N. ARNOLD, F. BREZZI, M. FORTIN, A stable finite element for the Stokes equations, Calcolo 21, (1984), 337. 
$\mathrm{N}=199, \mathrm{RN}=500$, Time $=11.5$

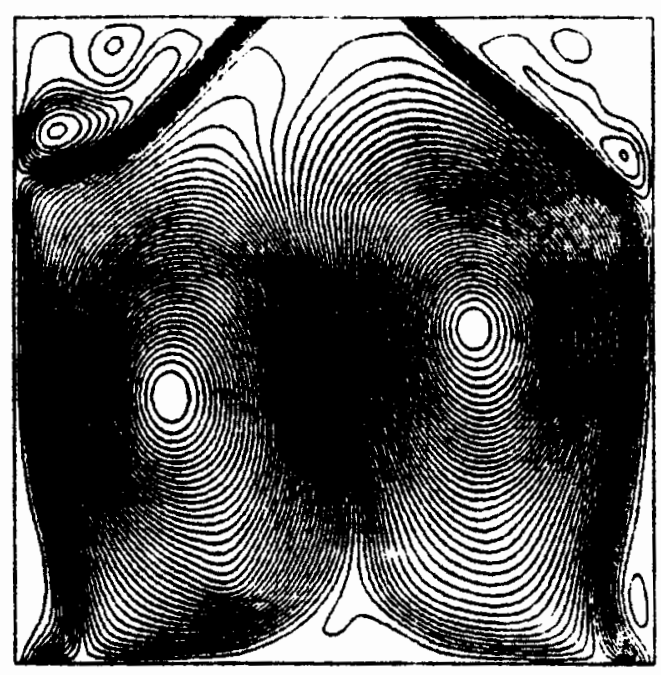

Figure 8.7 (a)

Streamlines $(t=11.5)$
$N=199 . \quad R N=500$, Time $=11.5$

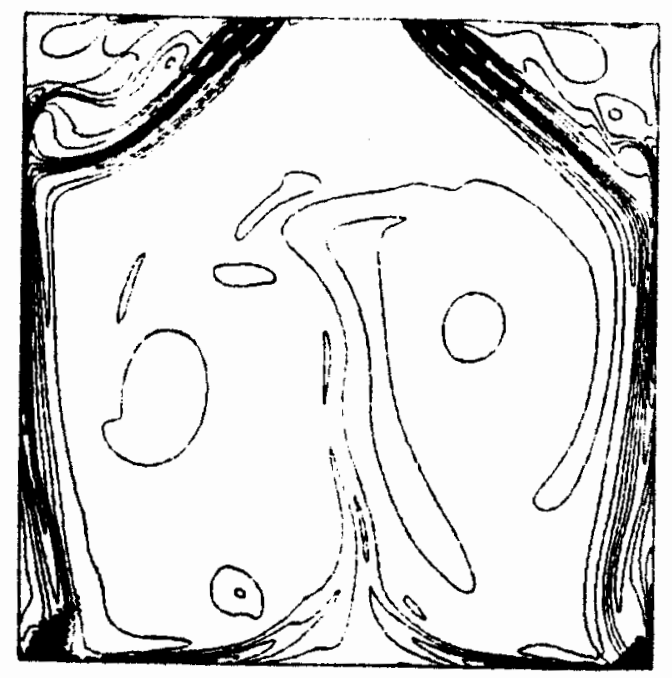

Figure 8.7 (b)

Vorticity contours $(t=11.5)$
$\mathrm{N}=199, \mathrm{RN}=500$, Time $=13.0$

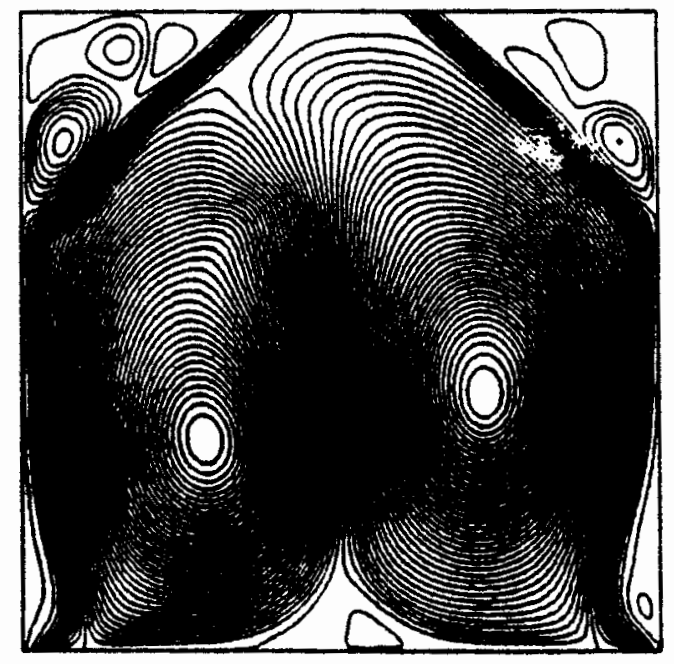

Figure $8.8 \quad$ (a)

Streamlines $(t=13.0)$
$\mathrm{N}=199, \mathrm{RN}=500$, Time $=13.0$

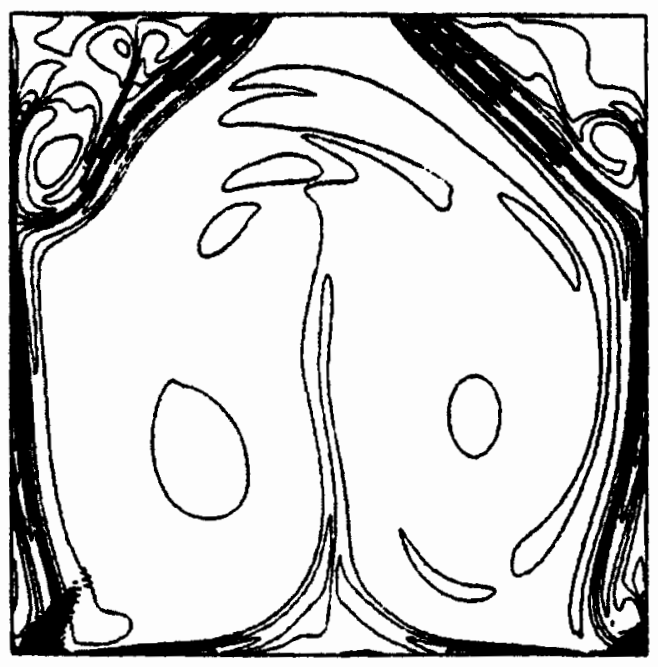

Figure $8.8 \quad$ (b)

Vorticity contours $(t=13.0)$ 
$N=199, R N=500$, 'Tine $=2.5$

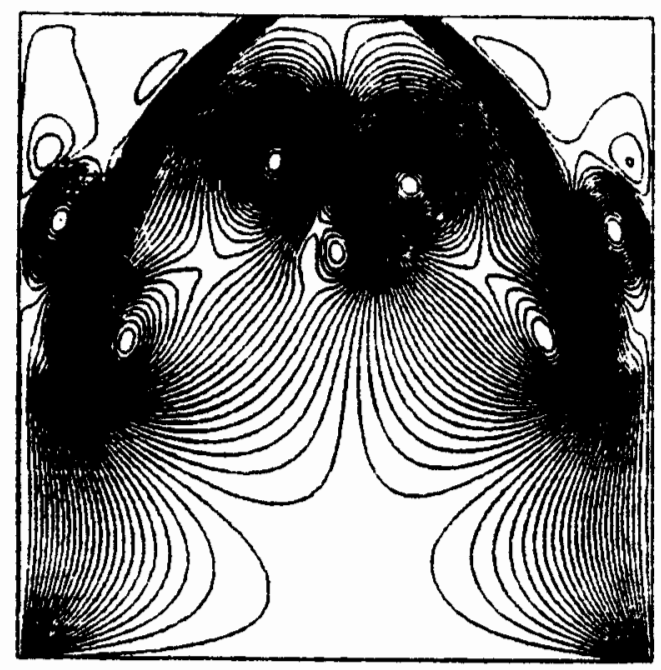

Figure 8.5 (a)

Streaml ines $(t=2.5)$

$N=199, R N=500$, Time $=3.0$

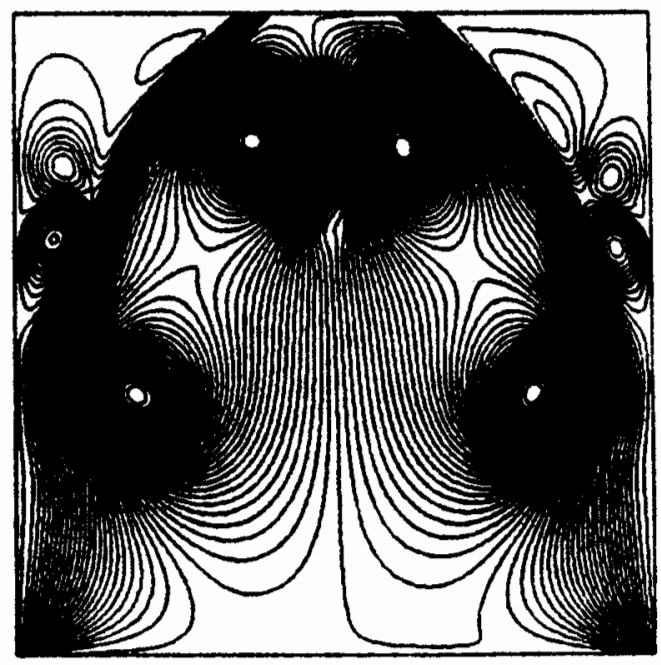

Figure 8.6 (a)

Streamlines $(t=3.0)$
$N=199, R N=500$, Tine $=2.5$

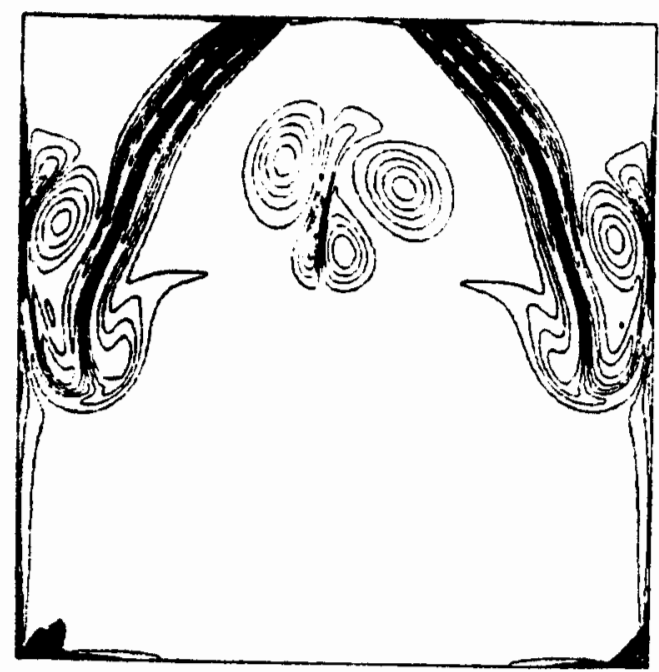

Figure 8.5 (b)

Vorticity contours $(t=2.5)$

$N=199, R N=500$, Time $=3.0$

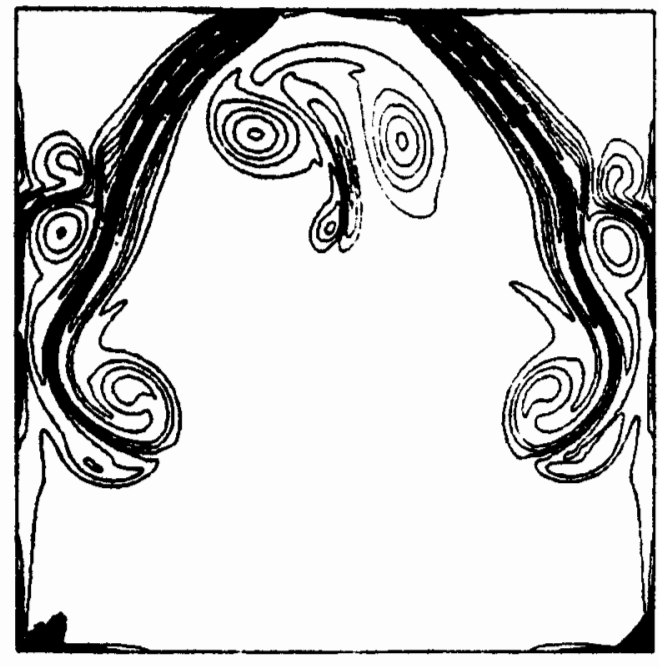

Figure 8.6 (b)

Vorticity contours $(t=3.0)$ 
$\mathrm{N}=199, \mathrm{RN}=500$, Time $=1.5$

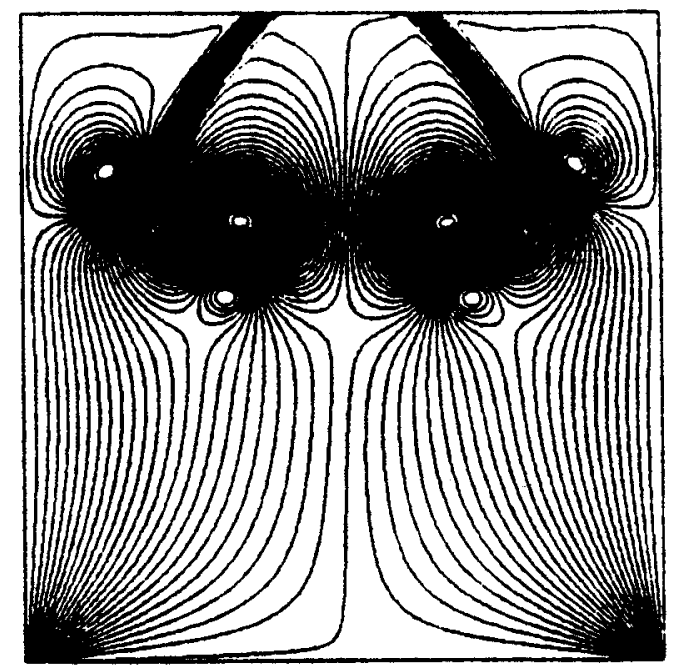

Figure 8.3 (a)

Streamlines $(t=1.5)$

$\mathrm{N}=199, \mathrm{RN}=500$, Time $=2.0$

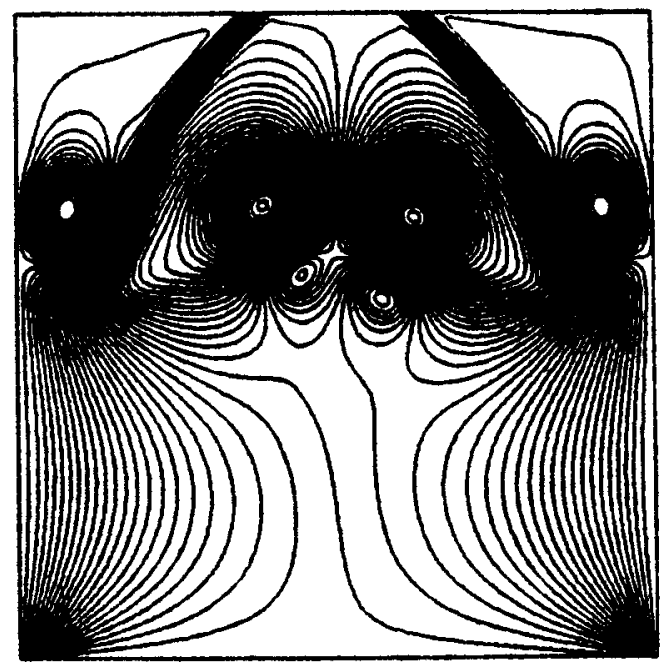

Figure 8.4 (a)

Streamlines $(t=2.0)$
$N=199, R N=500$. Time $=1.5$

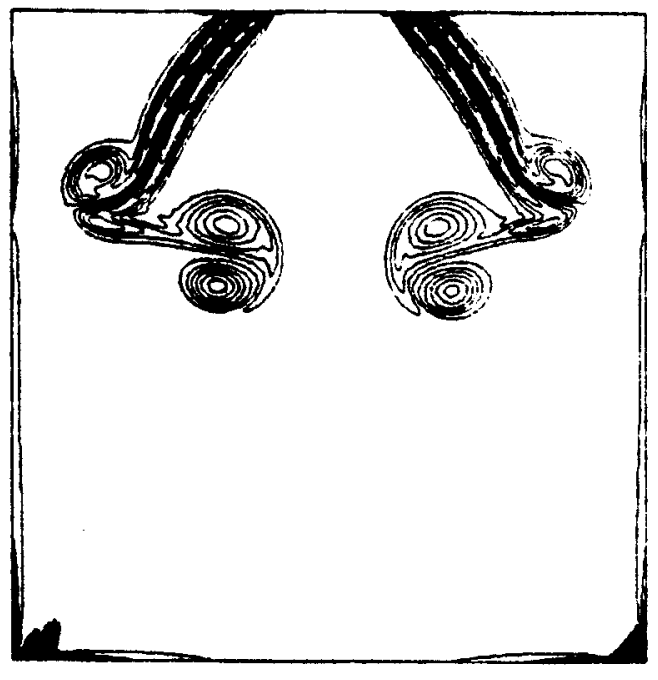

Figure 8.3 (b)

Vorticity contours $(t=1.5)$

$N=199, R N=500$, Time $=2.0$

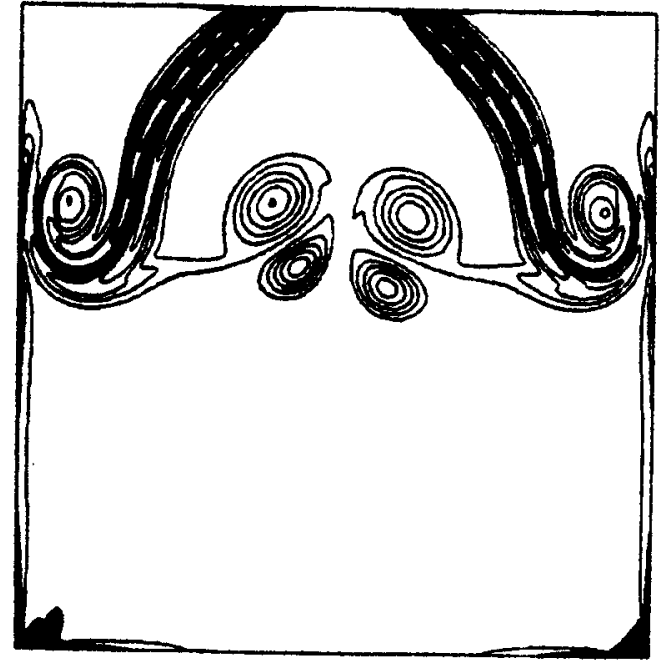

Figure 8.4 (b)

Vorticity contours $(t=2.0)$ 
$\mathrm{N}=199, \mathrm{RN}=500$, Time $=0.5$

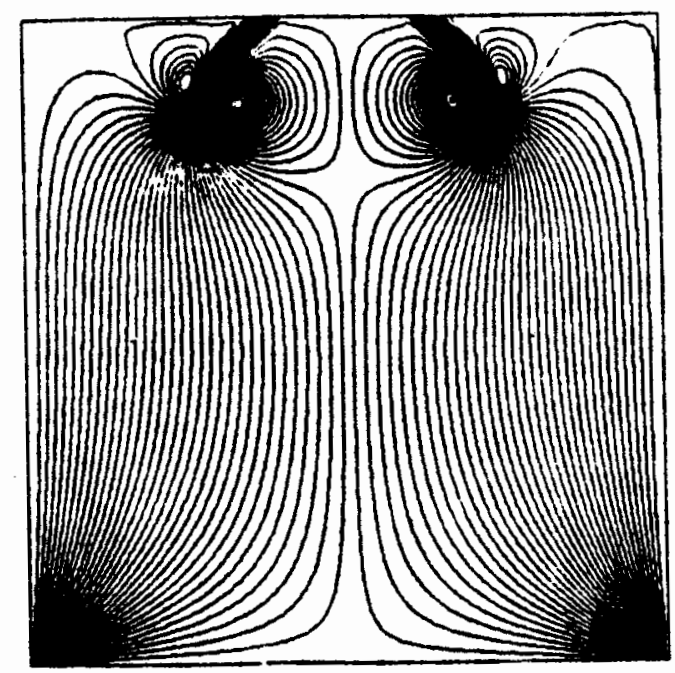

Figure 8.1 (a)

Streamlines $(t=0.5)$
$\mathrm{N}=199 . \mathrm{RN}=500$. Time $=0.5$

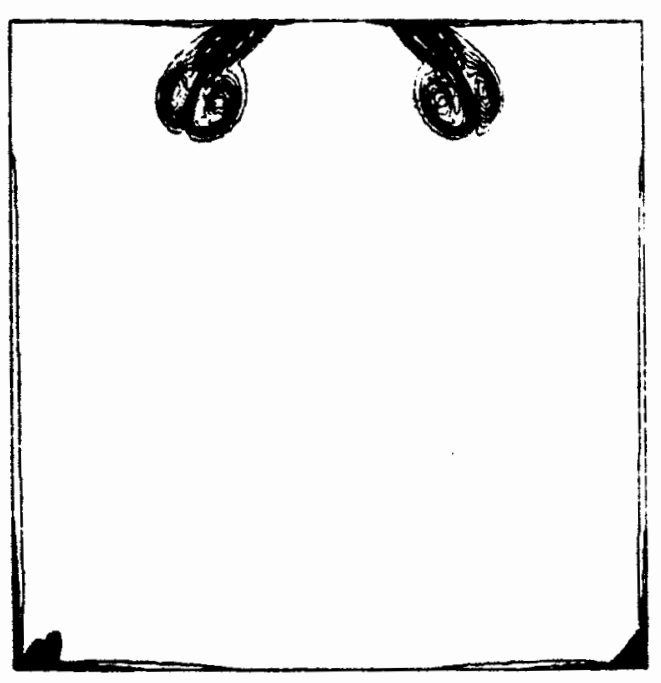

Figure 8.1 (b)

Vorticity contours $(t=0.5)$

$\mathrm{N}=199, \mathrm{RN}=500$, Time $=1.0$

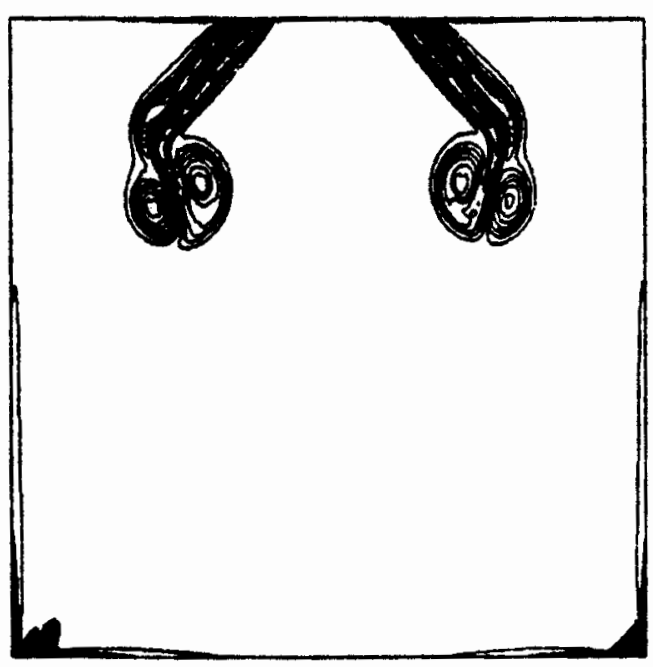

Figure 8.2 (b)

Vorticity contours $(t=1.0)$ 
Linergy

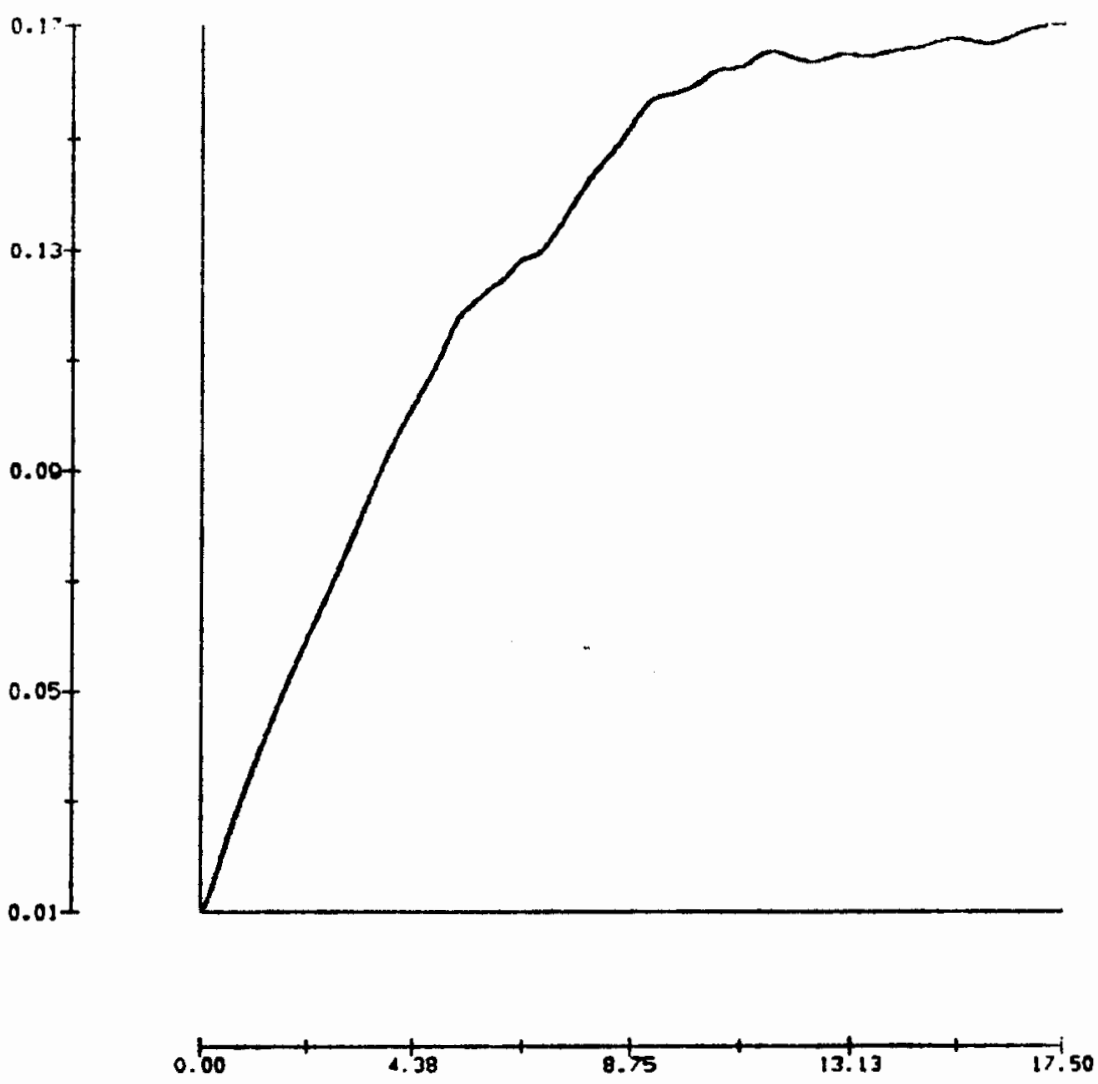

Figure 8.9

Variation of the kinetic energy 